\title{
Rossby Waves in the Tropical North Pacific and Their Role in Decadal Thermocline Variability
}

\author{
A. Capotondi And M. A. Alexander \\ NOAA-CIRES Climate Diagnostics Center, Boulder, Colorado
}

(Manuscript received 6 June 2000, in final form 15 May 2001)

\section{ABSTRACT}

\begin{abstract}
A band of enhanced thermocline variability at $10^{\circ}-15^{\circ} \mathrm{N}$ in the Pacific found in nature also occurs in an ocean general circulation model forced with observed fluxes of momentum, heat, and freshwater over the period 195897. The variability in the model is primarily associated with long baroclinic Rossby waves characterized by periods in the decadal range (7-10 yr). The waves are forced by westward propagating Ekman pumping anomalies east of the date line and propagate at a speed of $\sim 13 \mathrm{~cm} \mathrm{~s}^{-1}$, which is slower than the phase speed of the first mode unforced baroclinic waves $\left(15-16 \mathrm{~cm} \mathrm{~s}^{-1}\right)$. West of the date line, the correlations between thermocline displacements and local Ekman pumping are relatively small, and the ocean signals have a phase speed of $\sim 20$ $\mathrm{cm} \mathrm{s}^{-1}$, very similar to the phase speed of the first baroclinic mode in the western half of the basin $(18-20 \mathrm{~cm}$ $\mathrm{s}^{-1}$ ). The phase speeds of the ocean model signals have been estimated using cospectral analysis, while the WKB approximation has been used to evaluate the phase speed of the baroclinic Rossby wave modes for the given model stratification. The thermocline displacements are coherent all the way across the basin in the $10^{\circ}-$ $15^{\circ} \mathrm{N}$ latitude band. After reaching the western boundary the signal appears to propagate along the boundary, both to the north and the south. Along the southern branch, the signal reaches the equator and propagates along the equator, contributing to low-frequency equatorial thermocline variability.
\end{abstract}

\section{Introduction}

Several recent studies have found evidence for climate variability on decadal timescales in both the tropical and extratropical Pacific (e.g., Trenberth 1990; Tanimoto et al. 1993; Graham 1994; Wang and Ropelewsky 1995; Mantua et al. 1997; Zhang et al. 1997). Two wellknown examples are the decade-long shift in the atmosphere-ocean system that began in late 1976 (Douglas et al. 1982; Nitta and Yamada 1989; Graham et al. 1994; Trenberth and Hurrell 1994; Yasuda and Hanawa 1997) and the persistence of warm conditions in the tropical Pacific in the first part of this decade (Goddard and Graham 1997). Several mechanisms involving oceanic processes have been proposed to explain decadal variability. Some of these mechanisms hypothesize midlatitude-to-equator oceanic teleconnections as well as atmospheric teleconnections (Lau and Nath 1994; Lau 1997; Gu and Philander 1997; Liu 1999; Zhang and Liu 1999). Other proposed mechanisms involve processes occurring within the tropical band (Kleeman and Power 1994; Münnich et al. 1991; Jin et al. 1994; Knutson and Manabe 1998; Schneider 2000).

Based on the analysis of a coupled atmosphere-ocean

Corresponding author address: A. Capotondi, NOAA-CIRES Climate Diagnostics Center, R/CDC1, 325 Broadway, Boulder, CO 80303-3328.

E-mail: mac@cdc.noaa.gov
GCM, Schneider (2000) has suggested a mechanism for decadal variability that relies on the advection of compensating temperature and salinity anomalies (spiciness anomalies) along isopycnal surfaces in the thermocline at $10^{\circ}$ to $15^{\circ} \mathrm{N}$. Changes in the trade winds accelerate (decelerate) the North Equatorial Current. The advection of mean temperature and salinity gradients along isopycnal surfaces by the perturbation flow produces the spiciness anomalies that are then advected westward and southward along the western boundary by the mean currents. At the equator, they affect the surface heat budget, initiate a relaxation (strengthening) of the trade winds, and give rise to the opposite phase of the cycle.

Observations of the temperature standard deviation in the thermocline are characterized by enhanced variability between $10^{\circ}$ and $15^{\circ} \mathrm{N}$, as illustrated in Fig. 1a, with a second area of large variance being associated with the Kuroshio extension at $\sim 37^{\circ} \mathrm{N}$. Enhanced variability in approximately the same latitude band has emerged in a numerical simulation performed with an Ocean General Circulation Model (OGCM) forced with observed atmospheric conditions over the period 195897, as shown in Fig. 1b. The thermocline variability in the model appears to be associated with baroclinic Rossby waves forced by anomalous Ekman pumping, a mechanism quite different than the purely advective mechanism hypothesized by Schneider (2000). A large fraction of the variability between $10^{\circ}$ and $15^{\circ} \mathrm{N}$ is char- 

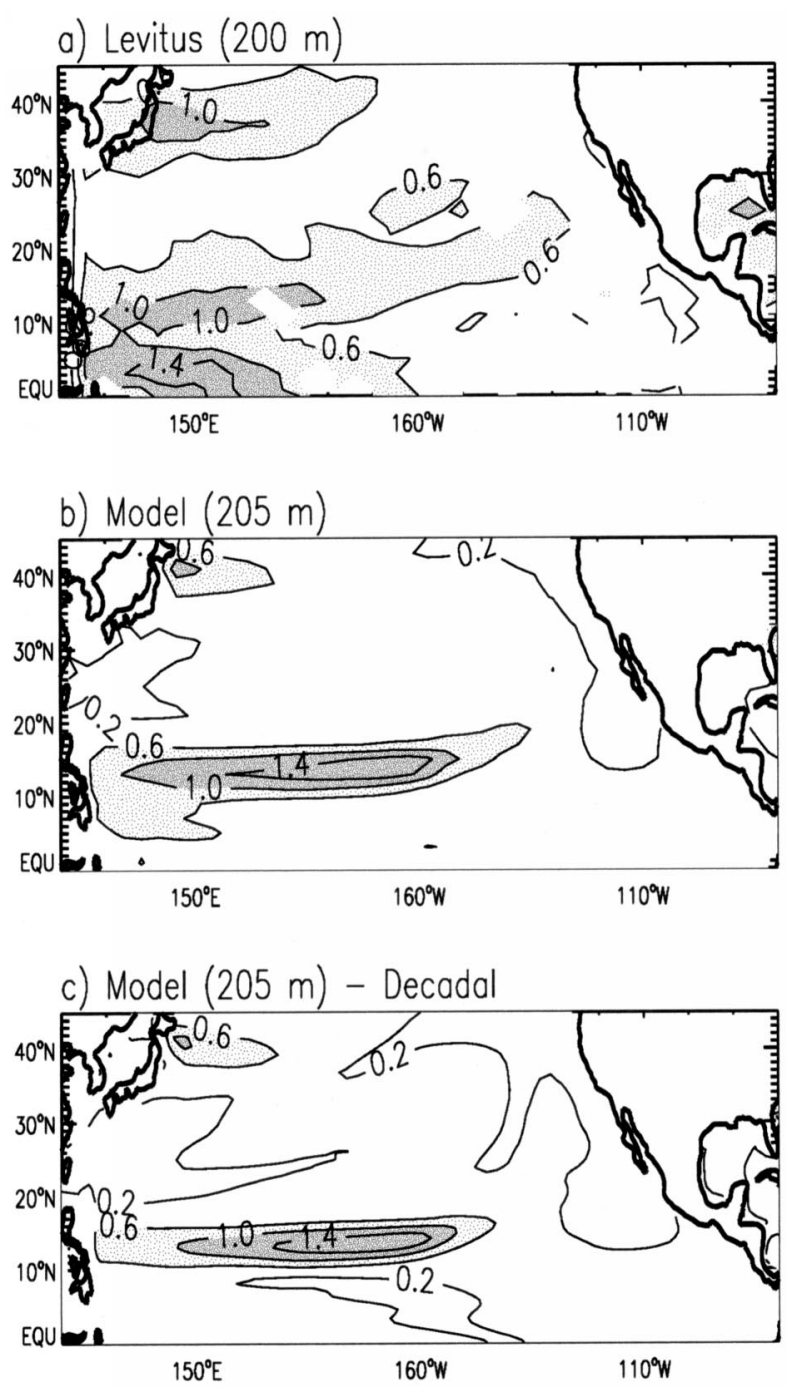

FIG. 1. (a) Temperature standard deviation at 200-m depth computed using data from Levitus. (b) Temperature standard deviation at a depth of $205 \mathrm{~m}$ (model level 13) in the model. (c) Standard deviation of the low-pass filtered temperature at $205 \mathrm{~m}$ in the model. Only periods longer than $7 \mathrm{yr}$ are retained. Contour interval is $0.4^{\circ} \mathrm{C}$. Values larger than $0.6^{\circ} \mathrm{C}$ are light shaded, while values larger than $1{ }^{\circ} \mathrm{C}$ are dark shaded.

acterized by timescales longer than $7 \mathrm{yr}$, as shown in Fig. 1c, where a low-pass filtered version of the model temperature variability is displayed. In this paper we will examine the nature and characteristics of the Rossby wave field at $10^{\circ}-15^{\circ} \mathrm{N}$, with special emphasis upon the origin of the long (decadal) timescales of the ocean signals.

Midlatitude theories of decadal variability rely upon oceanic Rossby wave dynamics for setting the timescale of the variability. Some of the proposed mechanisms (Latif and Barnett 1994, 1996; Robertson 1996; Jin 1997; Grötzner et al. 1998; Neelin and Weng 1999; Cessi 2000) consider coupled ocean-atmosphere interactions. Changes in the surface wind stress induce changes in the strength of the subtropical gyre, thus altering the northward heat advection by the western boundary current. The resulting SST anomalies affect the atmospheric circulation and ultimately produce changes in the surface wind stress. Since the atmospheric processes are relatively fast, it is the slow oceanic adjustment through Rossby wave propagation that is responsible for the decadal timescales. Although atmospheric feedbacks to SST anomalies can enhance the decadal signal, stochastic atmospheric forcing with a coherent basinwide spatial structure can also give rise to interdecadal timescales of variability (Jin 1997; Frankignoul et al. 1997; Neelin and Weng 1999). In the uncoupled cases the existence of a preferred length scale in the large-scale atmospheric forcing tends to excite oceanic Rossby waves with that length scale. The timescale of the variability then coincides with the Rossby wave period, resulting from the given wavelength and Rossby wave phase speed. An additional mechanism of midlatitude decadal variability involves coupled Rossby waves (Goodman and Marshall 1999), that is, atmospheric and oceanic waves that move westward in a phase-locked fashion. The spatial scale of the wave is again set by the atmosphere, and it is the scale at which Doppler shifted atmospheric Rossby waves propagate at the same speed as the underlying SST anomaly so that they can reinforce each other.

In the tropical North Pacific baroclinic Rossby waves have been investigated in several observational studies. White (1977) has considered the baroclinic Rossby waves forced by the annually varying wind stress curl in the latitude band $10^{\circ}-20^{\circ} \mathrm{N}$ using bathythermograph (BT) observations. Annual fluctuations of the $14^{\circ} \mathrm{C}$ isotherm in the tropical Pacific were studied by Meyers (1979) using a $11 / 2$ layer quasigeostrophic model (a model with an active upper layer over a motionless abyss). Kessler (1990, K90 hereafter) extended the analysis of baroclinic Rossby waves in the northern tropical Pacific to include interannual periods. He analyzed a more extensive BT dataset with respect to the one used by White (1977) and used the same $11 / 2$ layer quasigeostrophic model considered by Meyers (1979) to interpret the BT data. The above studies of tropical Rossby waves have mainly focused on annual and interannual periods, while longer timescales, in the decadal range, remain unexplored.

The main purpose of this paper is to understand the origin of the intense variability at $10^{\circ}-15^{\circ} \mathrm{N}$ in the $\mathrm{Pa}$ cific using the OGCM, which will lead us to the analysis of tropical Rossby waves with special emphasis on their generation, propagation, and area of influence. A detailed comparison of the variability in the $10^{\circ}-18^{\circ} \mathrm{N}$ latitude band between the model and observations indicate relatively good agreement between the two (Lysne and Deser 2002). Therefore, the model seems to be a suitable tool for the analysis of the variability around $13^{\circ} \mathrm{N}$. A study of North Pacific thermocline variability in a similar OGCM simulation has been carried out by Xie et 
al. (2000), but the main focus of that study was the wind-driven variability in midlatitudes.

The plan of the paper is the following: in section 2 we briefly describe the ocean model and its surface forcing. In section 3 we provide an overview of the ocean model variability around $13^{\circ} \mathrm{N}$, analyze its propagation characteristics, and examine the nature of its forcing. In section 4 we provide a dynamical interpretation of the variability in terms of wind-forced baroclinic Rossby waves, while in section 5 we analyze the propagation of the thermocline anomalies from $13^{\circ} \mathrm{N}$ to the equator, and from the equator to $13^{\circ} \mathrm{N}$ along the eastern boundary. In section 6 we discuss the origin of the long ("decadal") timescale of the waves. We conclude in section 7 .

\section{The model}

The ocean model used for this study is the NCAR ocean model (NCOM) that has been described in detail in Large et al. (1997), Gent et al. (1998), and Large et al. (2001). In this section we only provide a brief summary of the basic model characteristics and information about the surface forcing used for the numerical simulation analyzed here.

NCOM is derived from the Geophysical Fluid Dynamics Laboratory (GFDL) Modular Ocean Model with the addition of a mesoscale eddy flux parameterization along isopycnal surfaces (Gent and McWilliams 1990) and a nonlocal planetary boundary layer parameterization (Large et al. 1994). The model is global, with a horizontal resolution of $2.4^{\circ}$ in longitude and varying resolution in latitude, ranging from $0.6^{\circ}$ near the equator to $1.2^{\circ}$ at high latitudes. The model version used for this study includes an anisotropic viscosity parameterization (Large et al. 2001) with enhanced viscosity close to ocean boundaries and much weaker viscosity in the ocean interior.

The surface forcing includes momentum, heat, and freshwater fluxes for the period 1958-97. The wind stress is computed from the reanalyses fields produced at the National Centers for Environmental Prediction (NCEP; Kalney et al. 1996) using bulk formulas. The sensible and latent heat fluxes are computed from the NCEP winds and relative humidity and the model's SSTs using standard air-sea transfer equations (Large and Pond 1982; Large et al. 1997). Sensible and latent heat fluxes depend on the difference between SST and surface air temperature. Since SST and air temperature closely track each other, when observed air temperatures are used in bulk formulas, as in the present model simulation, the model's SST is damped toward observations (Haney 1971). The relaxation timescale is relatively short (30-60 days for typical mixed layer depths), so that the SST in the model can be expected to be strongly constrained by the surface forcing rather than by the interior ocean dynamics.

Cloud fraction and solar radiation are derived from the International Satellite Cloud Climatology Project
(ISCCP) dataset (Bishop and Rossow 1991; Rossow and Schiffer 1991) when the data coverage is adequate (1984-91), while the ISCCP monthly climatology is used prior to 1984 and after 1991. Precipitation information is obtained by combining microwave sounding unit (MSU) monthly observations (Spencer 1993) and Xie and Arkin (1996) observations from 1979 to 1993, while monthly climatologies of the two datasets are used prior to 1979. From 1993 to 1997 the MSU climatology is combined with the Xie and Arkin (1996) monthly values. MSU observations are used in rectangular regions in the tropical Pacific and Indian oceans, as well as along the Alaskan coast where the precipitation values of the Xie-Arkin dataset are believed to be too large. In the Pacific, the rectangular region where MSU observations are used extends approximately from $20^{\circ} \mathrm{S}$ to $20^{\circ} \mathrm{N}, 100^{\circ} \mathrm{E}$ to $120^{\circ} \mathrm{W}$. Outside these regions the XieArkin data are used, and a smooth transition between the two datasets is implemented.

The numerical simulation is started from an initial condition obtained from a preliminary climatological integration, so that the initial model state is not too different from the mean state characteristic of the 40$\mathrm{yr}$ experiment. Then the model was run for two 40-yr cycles, the second cycle starting from the conditions achieved at the end of the first 40-yr segment. The mismatch between the model state and the forcing at the beginning of the second cycle did not seem to produce any long-term transient. Here we analyze the output for the second 40-yr period using monthly and annual mean values. Some residual drift in temperature and salinity appears to be confined to depths larger than approximately $500 \mathrm{~m}$ (S. Yeager 2000, personal communications, http:/www.cgd.ucar.edu/oce/Yeager).

\section{Ocean model variability at $10^{\circ}-15^{\circ} \mathrm{N}$}

\section{a. Horizontal and vertical structure}

In Fig. 2 we show aspects of the model variability along the mean $25.5 \sigma_{\theta}$ isopycnal, computed from the 40 years of model output. This isopycnal lies in the core of the thermocline, where the largest temperature variability is found (see Fig. 3). The $25.5 \sigma_{\theta}$ isopycnal outcrops at midlatitudes around $35^{\circ}-37^{\circ} \mathrm{N}$ in winter and achieves its largest depth in the recirculation area in the western Pacific between $20^{\circ}$ and $30^{\circ} \mathrm{N}$ (Fig. 2a). Between $10^{\circ}$ and $15^{\circ} \mathrm{N}$, the northern flank of the intertropical convergence zone, the isopycnal depth increases from approximately $100 \mathrm{~m}$ in the east to $200 \mathrm{~m}$ in the west (see also Fig. 3). Temperature variability along this isopycnal (Fig. 2b) is characterized by a subducting signal originating at the winter outcrop between $\sim 180^{\circ}$ and $140^{\circ} \mathrm{W}$ and extending southwestward, as indicated by the dash-dot line in Fig. 2b. The subducted thermal anomalies decay away from the source region, and their amplitude is largely reduced before reaching the Trop- 

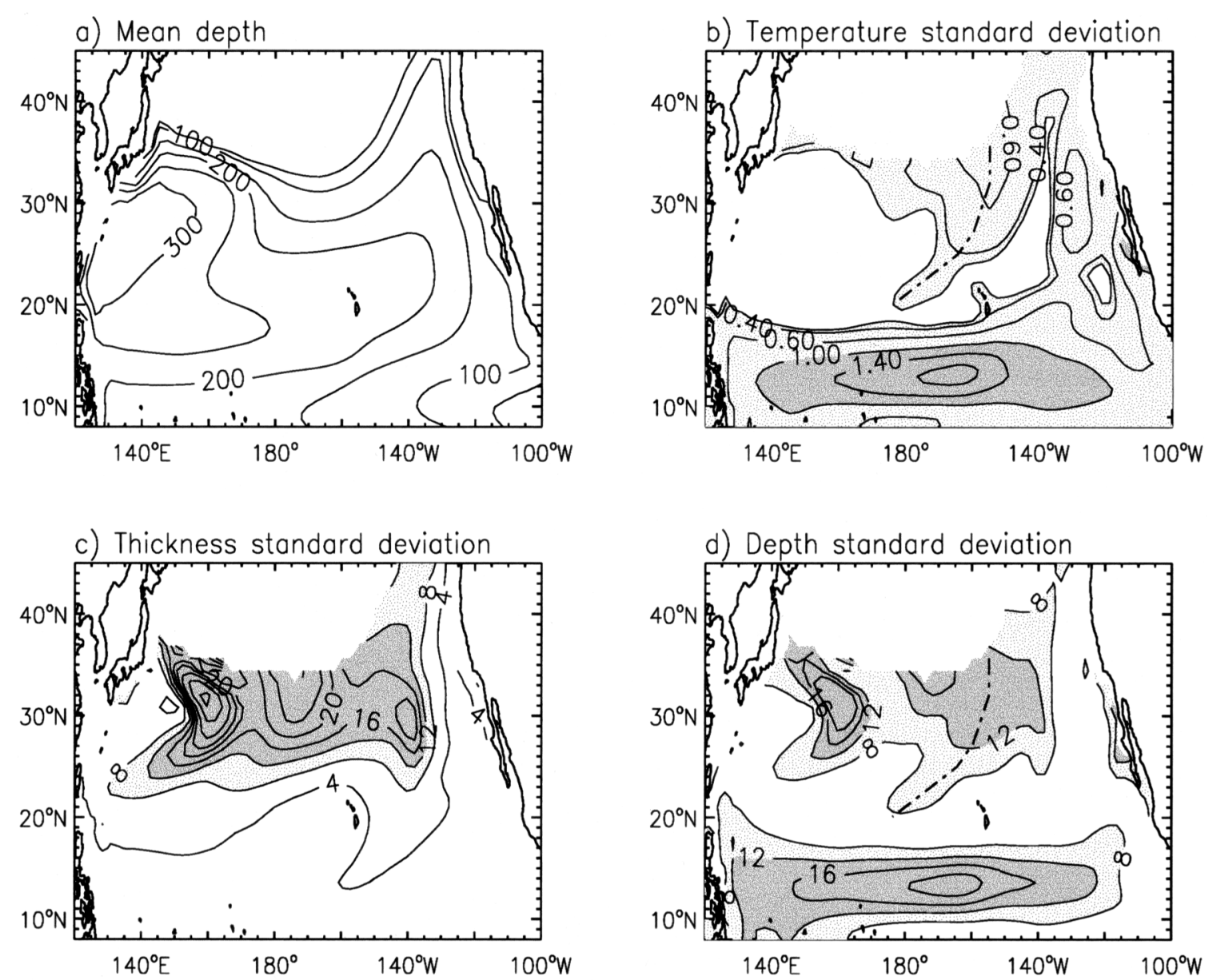

FIG. 2. (a) Mean depth of the $25.5 \sigma_{\theta}$ isopycnal. Contour interval is $50 \mathrm{~m}$. (b) Temperature standard deviation along the mean $25.5 \sigma_{\theta}$ surface. Units are ${ }^{\circ} \mathrm{C}$. Values larger than $0.35^{\circ} \mathrm{C}$ are light shaded, while values larger than $1{ }^{\circ} \mathrm{C}$ are dark shaded. (c) Standard deviation of the thickness of the layer bounded by the mean $25.2 \sigma_{\theta}$ and the $25.8 \sigma_{\theta}$ isopycnals. Contour interval is $4 \mathrm{~m}$ between 4 and $24 \mathrm{~m}$, and 10 $\mathrm{m}$ for values larger than $30 \mathrm{~m}$. Values larger than $8 \mathrm{~m}$ are light shaded, while values larger than $12 \mathrm{~m}$ are dark shaded. (d) Standard deviation of the depth of $25.5 \sigma_{\theta}$ isopycnal. Contour interval is $4 \mathrm{~m}$. Values larger than $8 \mathrm{~m}$ are light shaded, while values larger than $12 \mathrm{~m}$ are dark shaded. The dot-dashed line in (b) and (d) defines the position of largest thermal variability at each latitude, as an indication of the propagation pathway of the subducted signal.

ics, in agreement with the observational results of Schneider et al. (1999). Notice that the temperature standard deviation in Fig. $2 b$ is computed along the mean $25.5 \sigma_{\theta}$ isopycnal. Thus, the temperature anomalies in Fig. $2 \mathrm{~b}$ are not necessarily salinity compensated.

A second area of enhanced variance is the quasi-zonal band between $10^{\circ}$ and $15^{\circ} \mathrm{N}$, the largest signal, and the one that we are interested in understanding. The core is located around $13^{\circ} \mathrm{N}, 180^{\circ}-150^{\circ} \mathrm{W}$, with maximum values close to $2^{\circ} \mathrm{C}$. The temperature anomalies are associated with large isopycnal displacements, with standard deviations as large as $20 \mathrm{~m}$ (Fig. 2d). The changes in the isopycnal depth exclude the possibility that the variability considered here is primarily due to anomalous advection of compensated temperature and salinity anomalies (spiciness anomalies) along isopycnals. In fact, the temperature standard deviation along the time varying $25.5 \sigma_{\theta}$ isopycnal (not shown), a measure of spiciness, is negligible. Therefore, the large temperature (and salinity, not shown) anomalies around $13^{\circ} \mathrm{N}$ can either be due to displacements of the thermocline as a whole, associated with purely mechanical forcing by the winds, or they can result from diabatic forcing through anomalous heat and freshwater fluxes. In this second case, the uncompensated temperature changes would be accompanied by mass exchange between adjacent layers of fluid and result in changes in layer thickness. For the layer bounded by the 25.2 and $25.8 \sigma_{\theta}$ isopycnals, Fig. $2 \mathrm{c}$ shows that in the $10^{\circ}-15^{\circ} \mathrm{N}$ latitude band the thickness standard deviation is only a small fraction of the depth standard deviation, supporting the idea that the variability in this tropical band is mainly associated with adiabatic processes.

Large variability in the $10^{\circ}-15^{\circ} \mathrm{N}$ latitude band is also found by Xie et al. (2000) in a numerical simulation performed with the GFDL ocean model forced with 

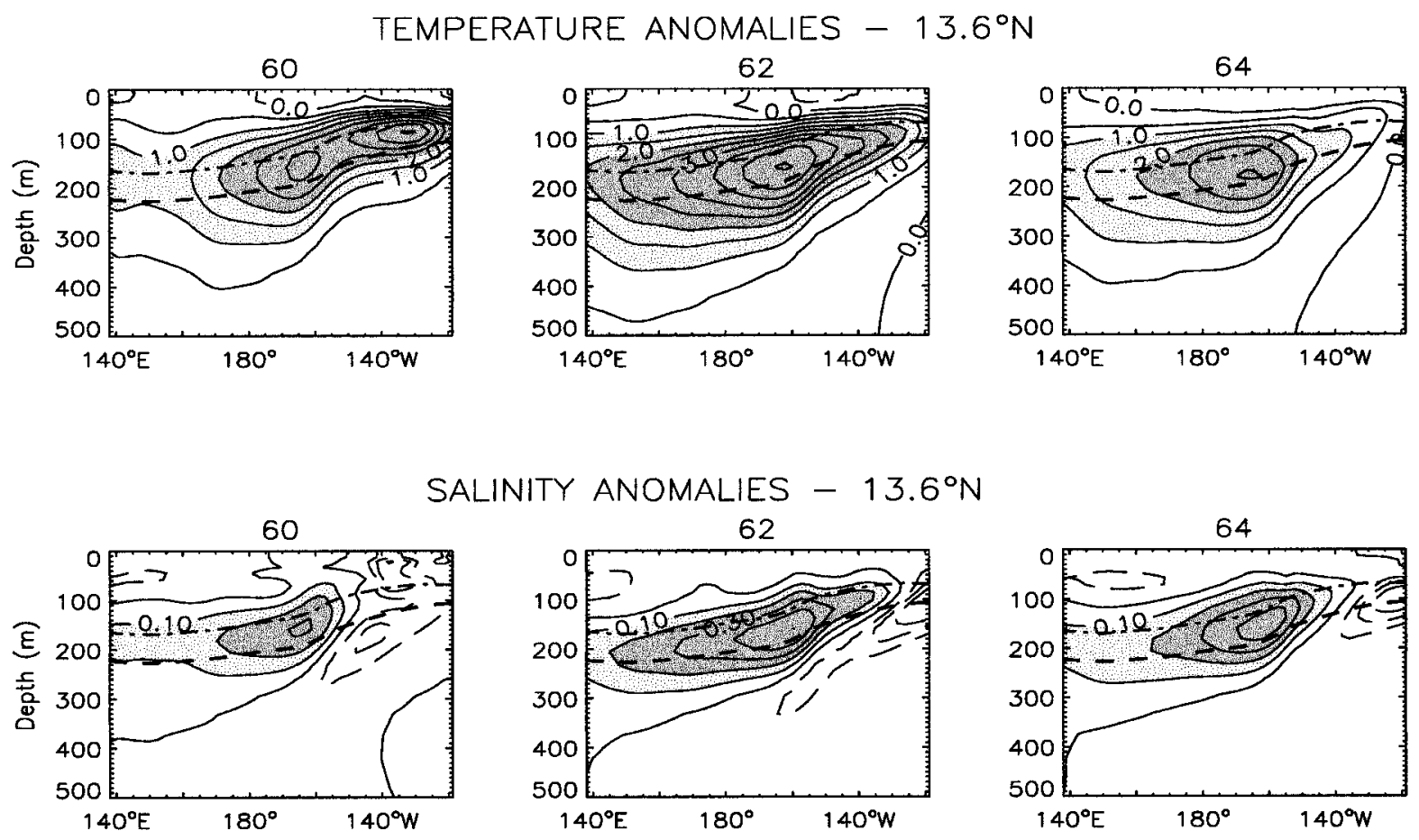

SALINITY ANOMALIES $-13.6^{\circ} \mathrm{N}$
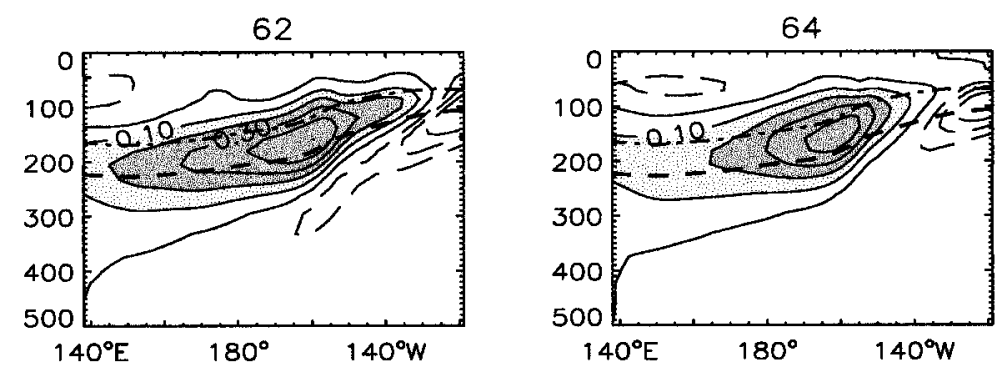

FIG. 3. Zonal sections of temperature (top panels) and salinity (bottom panels) anomalies at $13.6^{\circ} \mathrm{N}$ for the years 1960,1962 , and 1964 . Positive values are indicated by solid lines, while negative values are dashed. Contour interval for temperature is $0.5^{\circ} \mathrm{C}$. Values larger than $1^{\circ} \mathrm{C}$ are light shaded, and values larger than $2^{\circ} \mathrm{C}$ are dark shaded. Contour interval for salinity is $0.1 \mathrm{ppt}$. Values larger than $0.1 \mathrm{ppt}$ are light shaded, while values larger than $0.2 \mathrm{ppt}$ are dark shaded. The thick short-dashed line indicates the mean $25.5 \sigma_{\theta}$ isopycnal, while the dotdashed line shows the mean depth of the $20^{\circ} \mathrm{C}$ isotherm.

anomalous wind stresses from the NCEP-NCAR reanalyses over the period 1958-97. The numerical simulation of Xie et al. (2000) is very similar to the one analyzed here, but no anomalous heat or freshwater forcing is included, so that the enhanced variability around $13^{\circ} \mathrm{N}$ can only be a purely mechanical wind-forced phenomenon, in agreement with our interpretation.

The structure of the temperature and salinity anomalies in the vertical plane is also consistent with vertical and horizontal displacements of the thermocline. Zonal sections of temperature (top panels) and salinity (bottom panels) along $13.6^{\circ} \mathrm{N}$ are shown in Fig. 3 for years 1960, 1962 , and 1964 , as an example. The signals are largest in the thermocline between about $100-250 \mathrm{~m}$. These anomaly patterns in the zonal-vertical plane are typical of the whole 40-yr period. The years chosen in Fig. 3 correspond to a period of large deepening of the thermocline. At the peak of the event (year 1962) temperature anomalies are as large as $4^{\circ} \mathrm{C}$, and salinity anomalies are as large as $0.45 \mathrm{ppt}$, and are associated with an isopycnal deepening as large as $40 \mathrm{~m}$. Notice that temperature anomalies are positive everywhere in the zonal section at $13.6^{\circ} \mathrm{N}$, due to the fact that at these latitudes mean temperatures decrease with depth. Compared with temperature, salinity anomalies are both positive and negative, reflecting the more complex distribution of the mean salinity. Salinity anomalies are positive in the core of the thermocline west of $\sim 140^{\circ} \mathrm{W}$ where the vertical salinity gradient is positive upward, but they are negative close to the surface and close to the eastern boundary, where the mean salinity increases with depth. The largest temperature and salinity anomalies in Fig. 3 are both positive, indicating the possibility of compensating temperature and salinity effects on density. The locally linearized equation of state, $\rho=-\alpha T$ $+\beta S$, has $\alpha \sim 0.25 \mathrm{~kg} \mathrm{~m}^{-3}{ }^{\circ} \mathrm{C}^{-1}$ and $\beta=0.77 \mathrm{~kg} \mathrm{~m}^{-3}$ $\mathrm{ppt}^{-1}$ so that the density perturbation induced by a salinity anomaly of $0.4 \mathrm{ppt}$ is about $30 \%$ of the density change induced by a thermal anomaly of $4^{\circ} \mathrm{C}$. Thus, temperature variability tends to control density variability at these latitudes.

\section{b. Propagation characteristics}

Figure $4 \mathrm{~b}$ shows the Hovmöller diagrams of the 25.5 $\sigma_{\theta}$ depth anomalies $(\eta)$ along $13.6^{\circ} \mathrm{N}$. The Hovmöller diagram of the anomalous Ekman pumping $\left(W_{E}\right)$ along the same latitude is also shown for comparison in Fig. $4 \mathrm{a}$, and will be discussed in section 3c, while Figs. 4c and $4 \mathrm{~d}$ are obtained as solutions of a simple model and will be discussed in section 4 . The depth anomalies in Fig. 4b show a pronounced trend with predominantly positive values (deepening of the isopycnal) during the first 20 years becoming progressively more negative (shallowing of the isopycnal) during the second half of the 40 -yr period. The same trend is present in the anom- 

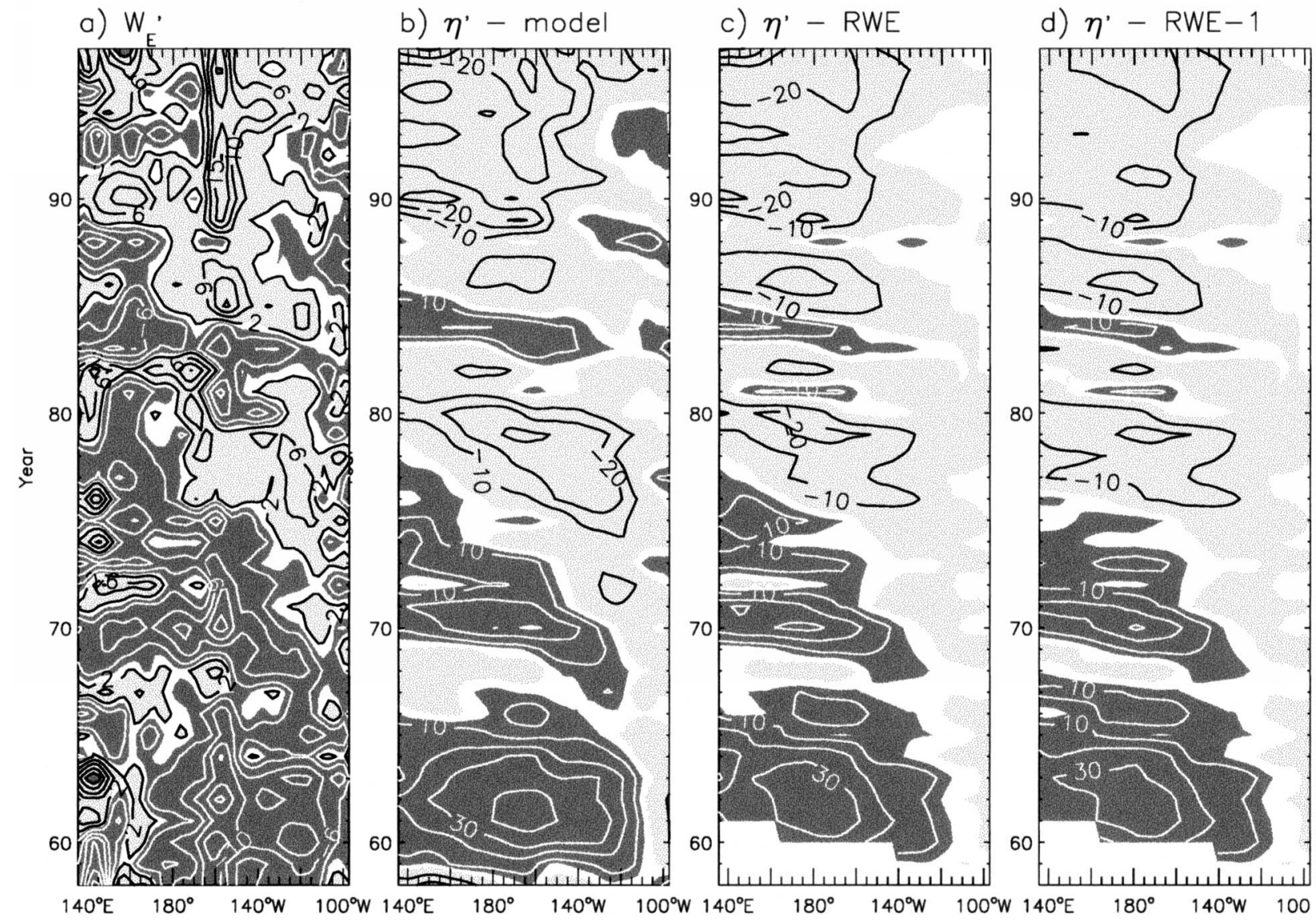

FIG. 4. (a) Hovmöller diagram of annual anomalies of Ekman pumping $\left(W_{E}\right)$ at $13.6^{\circ} \mathrm{N}$. Countour interval is $5 \times 10^{-5} \mathrm{~cm} \mathrm{~s}^{-1}$ for absolute values larger than $10 \times 10^{-5} \mathrm{~cm} \mathrm{~s}^{-1}$, and $4 \times 10^{-5} \mathrm{~cm} \mathrm{~s}^{-1}$, for absolute values smaller than $10 \times 10^{-5} \mathrm{~cm} \mathrm{~s}^{-1}$. Dark gray indicates negative values, while light gray is used for positive values. (b) Hovmöller diagram of $25.5 \sigma_{\theta}$ annual depth anomalies $(\eta)$ at $13.6^{\circ} \mathrm{N}$. Contour interval is $10 \mathrm{~m}$. Dark gray indicates positive values, while light gray is used for negative values. (c) Hovmöller diagram of annually averaged isopycnal depth anomalies along $13.6^{\circ} \mathrm{N}$ computed from equation (3) using the observed Ekman pumping at this latitude. (d) Same as in (c), but with Ekman pumping anomalies set to zero west of the date line. Contour intervals and shading in (c) and (d) as in (b).

alous Ekman pumping and will be discussed in section 3c.

Superimposed on the trend, the $\eta$ Hovmöller diagram shows a banded structure with positive and negative anomalies, which alternate approximately every 7-10 years. A negative slope in the phase lines, indicative of westward propagation, can be identified in some cases, for example the positive event starting around 1966-68 at $120^{\circ} \mathrm{W}$ and the negative event covering the period 1970-80 in the eastern basin.

To quantify this visual impression of westward propagation we use cross-spectral analysis. We consider a series of boxes, numbered from 0 to 9 from east to west, as illustrated in Fig. 5, and compute cross-spectra between the average $\eta$ time series for each independent pair of boxes. Monthly values were used, and the time series were detrended before computing the cross-spectra. The results are presented in Fig. 6 (solid line), which shows the coherence between $\eta$ in boxes $1-9$ and $\eta$ in box 0 , used here as a reference. The coherence between $W_{E}$ in boxes 1-9 and box 0 is also shown in Fig. 6 (dot- dash line). In the frequency band with periods from 7 to 10 years (identified by the vertical solid lines) the thermocline displacements remain significantly coherent at the $90 \%$ level with the thermocline variability in the easternmost box almost all the way to the western boundary. Notice that the $W_{E}$ anomalies also show significant coherence in the same spectral band over the first four boxes (approximately east of $180^{\circ}$, Fig. 5), thus justifying the special emphasis on this particular spectral band. We will further analyze the characteristics of the low-frequency $W_{E}$ variability in section 3c.

The time lags of the thermocline displacements in this frequency band (indicated in each panel, in years) increase progressively from east to west. Box 1 lags box 0 by approximately half a year, while the variability in box 9 lags the variability in box 0 by more than 2 years. We can use this lag information to estimate the phase speed of the disturbances by relating it to the distance between boxes. To increase the number of realizations we plot the lag between any independent pair of boxes against the distance between the box pair. The result is 


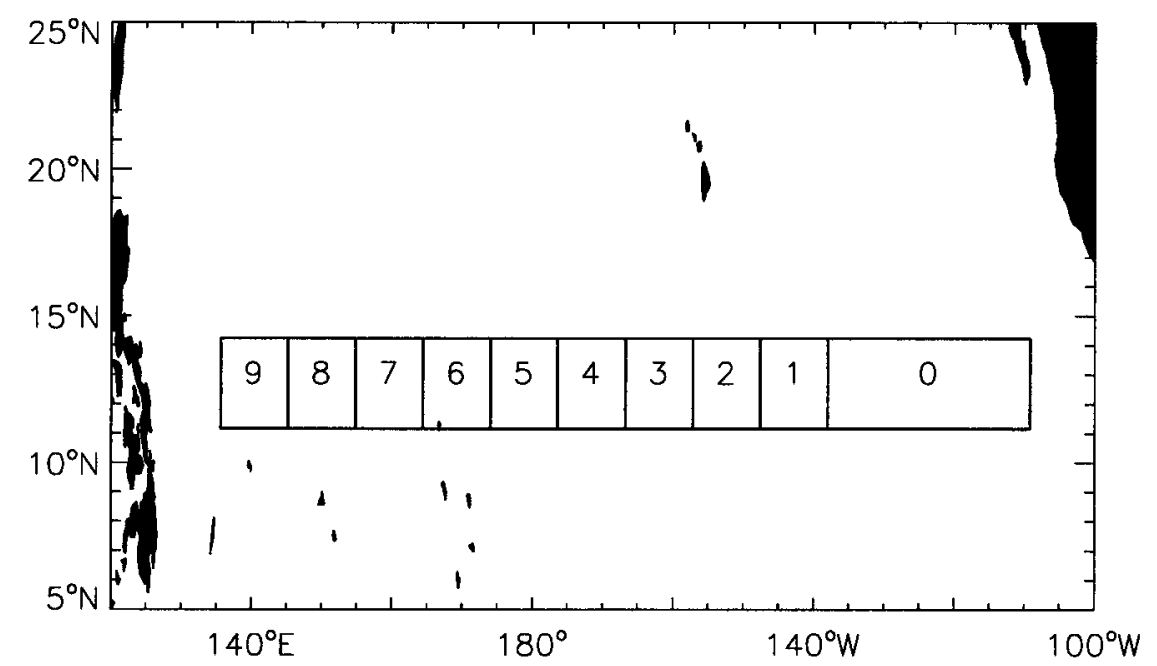

FIG. 5. Boxes used to compute average $25.5 \sigma_{\theta}$ depth anomalies and average Ekman pumping anomalies.

the scatter diagram shown in Fig. 7a from which we estimate, using a least squares fit, a phase speed of 15.1 $\mathrm{cm} \mathrm{s}^{-1}$. This value represents an average estimate across the Pacific at $13.6^{\circ} \mathrm{N}$. However, as seen in Figs. 2 and 3 , the thermocline deepens in the west, and these changes in stratification result in changes in wave phase speeds. In addition, the nature of the forcing is different in the eastern and western halves of the basin (section $3 \mathrm{c}$ ), suggesting that propagation speeds may also be different in these two areas. If we repeat the analysis of Fig. 7a for the area east of $175^{\circ} \mathrm{W}$ we obtain an estimate of $13.2 \mathrm{~cm} \mathrm{~s}^{-1}$ (Fig. $7 \mathrm{~b}$ ), while west of $175^{\circ} \mathrm{W}$ the propagation speed of the ocean signal increases to $\sim 19.7 \mathrm{~cm} \mathrm{~s}^{-1}$ (Fig. 7c).

The propagation of the signal in the 7-10 yr band can be concisely visualized with a dial plot, as shown in Fig. 8a. The variations of $\eta$ in box 0 (indicated by a dash-dot line in figure 8a) is used as the reference time series. The coherence between this time series and $\eta$ at each grid point in the frequency band of interest are given by the length of the arrows. Only coherences above the $90 \%$ significance level are plotted. Phase differences are given by the direction of the arrows. Arrows pointing due north correspond to zero lag, and positive lags are associated with a clockwise rotation of the arrows. Figure 8a shows a very well defined band of significant coherence from the eastern Pacific all the way to the western boundary. The coherence also appears to remain above the significance level along the western boundary, both to the north and the south of the latitude band of the incoming disturbances, indicating that after reaching the western boundary, approximately $2-3$ years later, the signal originating in the eastern Pacific continues along the boundary either as a coastal Kelvin wave (to the south) or as a perturbation advected by the mean flow. In particular, on the southern side, significant coherence can be found all the way to the equator. We further discuss the area of influence of the southern branch of the signal in section 5 .

The phase lags increase progressively from east to west as indicated by the clockwise rotation of the arrows. At the western boundary the signal is approximately $90^{\circ}$ out of phase with the signal in box 0 . This implies that the width of the basin at this latitude is approximately a quarter of the zonal wavelength. An alternate way of evaluating the zonal wavelength for the signal in the 7-10 yr spectral band is from the relationship $k=2 \pi / \lambda=\sigma / c_{R}$ (with $k$ being the zonal wavenumber, $\lambda$ the zonal wavelength, $\sigma$ the frequency, and $c_{R}$ the westward phase speed). Assuming $c_{R} \sim 16 \mathrm{~cm}$ $\mathrm{s}^{-1}$, and $\sigma=2 \pi(9 \mathrm{yr})^{-1}$, the value obtained for $\lambda$ is $\sim 45000 \mathrm{~km}$, consistent with the estimate from Fig. 8a. So the zonal wavelength is much larger than the basin width. Using phase variations to estimate the meridional wavelength is less straightforward because the meridional extent of the significantly coherent signal is limited. However, in Fig. 8a phases remain of the same sign over at least $5^{\circ}$ of latitude, which can be interpreted as a quarter of the meridional wavelength, suggesting a lower limit for the meridional wavelength of $\sim 20^{\circ}$. We will use these estimates of zonal and meridional wavelengths in section 4 to compute Rossby wave phase speeds in the model.

\section{c. Surface forcing}

Several observational studies have shown that annual and interannual Rossby waves in the Pacific ocean are influenced by Ekman pumping from the fluctuating wind stress curl (e.g., White 1977; Meyers 1979; White and Saur 1981, 1983; K90; Qiu et al. 1997). In particular, K90 has shown that south of $15^{\circ} \mathrm{N}$ the interannual variability of the depth of the $20^{\circ} \mathrm{C}$ isotherm is mainly forced by Ekman pumping in the ocean interior, while 

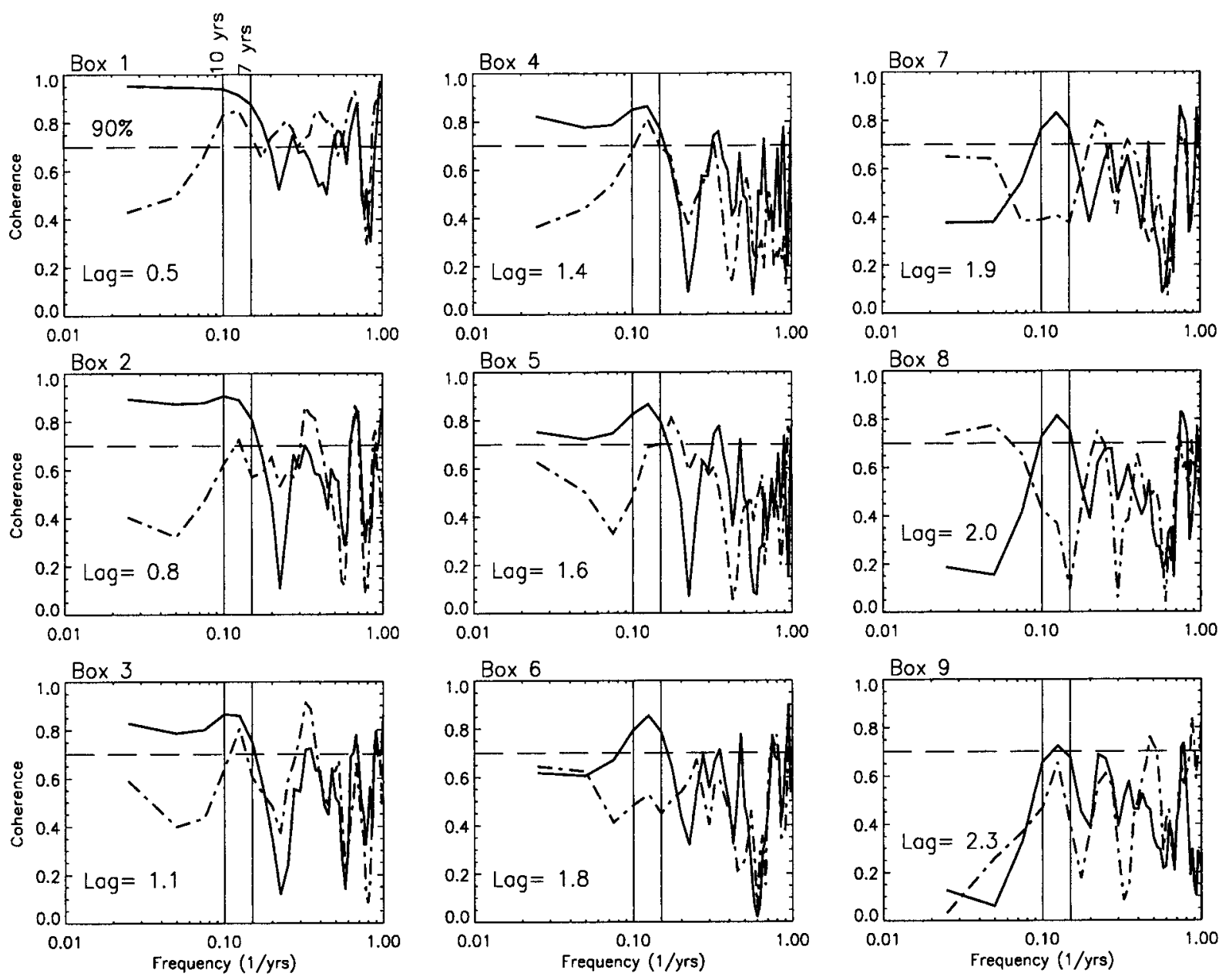

FIG. 6. Coherence between $25.5 \sigma_{\theta}$ depth anomalies in boxes 1 to 9 (from top to bottom, left to right) and the isopycnal depth anomaly in box 0 (thick solid lines), and coherence between $W_{E}$ in boxes $1-9$ and $W_{E}$ in box 0 (dot-dash line). Monthly values were used. Boxes are defined in Fig. 5. In each panel the thin vertical solid lines highlight the frequency bands with periods from 7 to $10 \mathrm{yr}$, and the dashed lines indicate the $90 \%$ significance level. Also, in each panel the time lag (in years) between the thermocline displacement in the corresponding box and the thermocline displacement in box 0 is indicated.

changes in isotherm depth along the eastern boundary decay very quickly away from the boundary. We expect that Ekman pumping plays an important role in the model variability at $10^{\circ}-15^{\circ} \mathrm{N}$. But where is the forcing located? Does it have a basin wide distribution or is it limited to some specific areas? Also, a striking aspect of the ocean variability in which we are interested is its relatively narrow meridional scale. Is this scale set by the forcing, that is, enhanced Ekman pumping variability in this latitude band, or is it associated with an enhanced ocean response? In order to address these issues we need to clearly assess the characteristics of the forcing.

We compute Ekman pumping $W_{E}$ at each model grid point from the wind stress $\tau=\left(\tau_{\lambda}, \tau_{\phi}\right)$ as

$$
W_{E}=\frac{1}{\rho_{0}} \mathbf{k} \cdot\left(\boldsymbol{\nabla} \times \frac{\boldsymbol{\tau}}{f}\right)
$$

where $\rho_{0}\left(=1025 \mathrm{~kg} \mathrm{~m}^{-3}\right)$ is the density of seawater, $\mathbf{k}$ is the unit vector in the vertical direction, $f$ is the Coriolis parameter, and $\boldsymbol{\nabla}$ is the gradient operator in spherical coordinates.

Figure 4 shows that there is a close correspondence between the evolution of the $25.5 \sigma_{\theta}$ depth anomalies (Fig. 4a) and the evolution of the Ekman pumping anomalies (Fig. $4 \mathrm{~b}$ ) along $13^{\circ} \mathrm{N}$, negative Ekman pumping anomalies being generally associated with positive depth anomalies (deepening of the isopycnal), and vice versa. However, the $W_{E}$ field is noisier than the $\eta$ field, and the correspondence between the two fields seems more pronounced in the eastern half of the basin. In fact, while the depth anomalies have a basinwide character, the $W_{E}$ anomalies originating in the east in most cases do not extend west of the date line, so in the western half of the basin there is often a mismatch between changes in isopycnal depth and local Ekman pumping. 
a) $\eta^{\prime}$, basin width

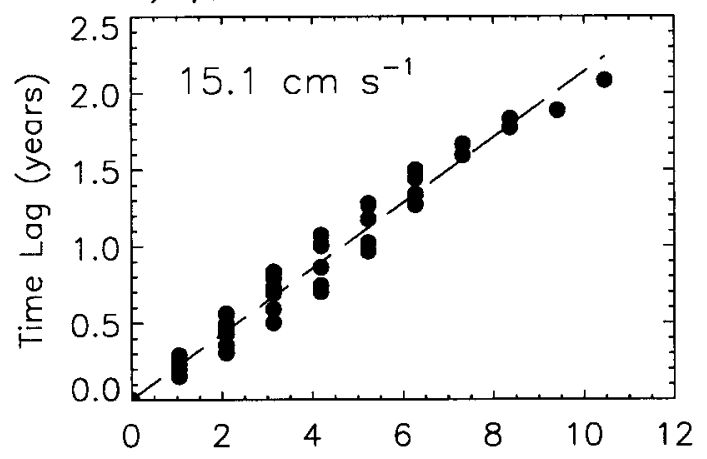

c) $\eta$, west of $175^{\circ} \mathrm{W}$

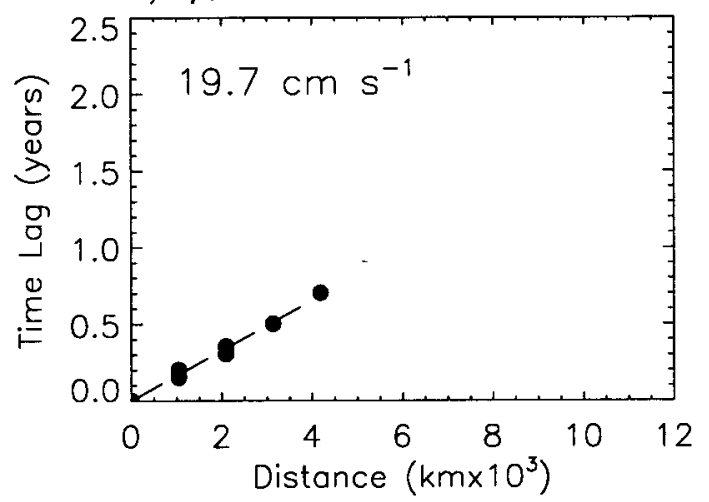

b) $\eta^{\prime}$, eost of $175^{\circ} \mathrm{W}$

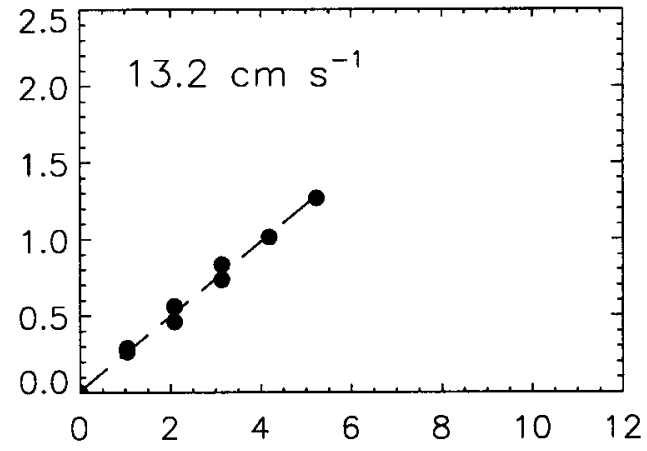

d) $W_{E}$, east of $175^{\circ} \mathrm{W}$

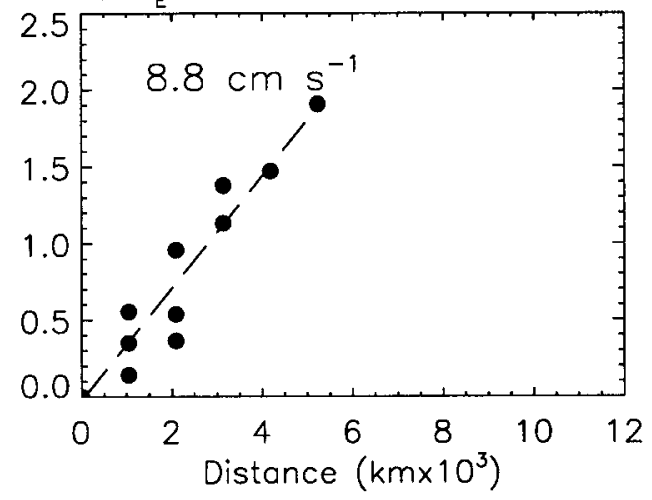

FIG. 7. (a) Time lag (in years) between each independent pair of boxes in Fig. 5 as a function of distance between the box pair. The time lag is computed by dividing the phase difference between each box pair in the 7-10 yr time range (the frequency band identified in figure 6 by the two vertical lines) by the corresponding frequency. The dashed line is derived using a least squares fit, its slope corresponding to a phase speed of $15.1 \mathrm{~cm} \mathrm{~s}^{-1}$. (b) Same as in (a) but considering only the boxes located east of $175^{\circ} \mathrm{W}$. (c) Same as in (a) but considering only the boxes located west of $175^{\circ} \mathrm{W}$. (d) Same as in (b) but for $W_{E}$.

This visual impression is confirmed by the correlation between the $\eta$ field and the $W_{E}$ field, as shown in Fig. $9 \mathrm{~b}$. The largest instantaneous correlations are found east of $175^{\circ} \mathrm{E}$, and the largest values are mainly confined in the $10^{\circ}-15^{\circ} \mathrm{N}$ latitude band. Does this area of higher correlations coincide with an area of particularly large forcing? The standard deviation of $W_{E}$ is shown in Fig. 9a. It shows a gradual increase with decreasing latitude due to the decrease of the Coriolis parameter. In the $10^{\circ}-15^{\circ} \mathrm{N}$ latitude band standard deviations tend to be larger west of the date line than east of the date line (apart from the isolated patch of large variance around $\left.160^{\circ} \mathrm{W}\right)$. Thus, the high correlations between the $W_{E}$ forcing and the thermocline variations in the eastern Pacific cannot be explained in terms of a larger amplitude of the forcing. We will explore the reasons for the large correlations by further analyzing the nature of the $W_{E}$ anomalies east of the date line later in this section, and then proposing a dynamical interpretation in section 4 .

A direct comparison of Ekman pumping and depth anomaly time series is shown in Fig. 10a, using annually averaged data. The two time series describe average variations over the area $11^{\circ}-14^{\circ} \mathrm{N}, 179^{\circ} \mathrm{E}-140^{\circ} \mathrm{W}$, in- dicated by the dash-dot line in Fig. 9b. For ease of comparison, both time series have been normalized to unit standard deviation. The correlation coefficient between the two time series is 0.86 . Superimposed on a trend, which is present in both time series, the ocean model signal shows a low-frequency modulation with a timescale close to decadal. The oceanic spectrum (Fig. $10 \mathrm{~b}$ ) is redder than the spectrum of the forcing, with enhanced power at periods longer than 7 years, the same frequency band that has emerged in the cross-spectral analysis as significantly coherent across the basin.

Notice that the time series in Fig. 10a show almost in-phase variations. Using monthly values, the largest correlation is found when the two time series are lagged by $\sim 2$ months (not shown). Since the Ekman pumping is proportional to the tendency of the thermocline depth, one would expect a quadrature relationship between the two time series in Fig. 10a, which would correspond to a time lag of 2-2.5 years for periods of 8-10 yr. Using cross-spectral analysis, one finds that over the spectral band where $W_{E}$ and $\eta$ are significantly coherent (from approximately 40 years to a few months, as shown in Fig. 10c) the phase difference increases from values 

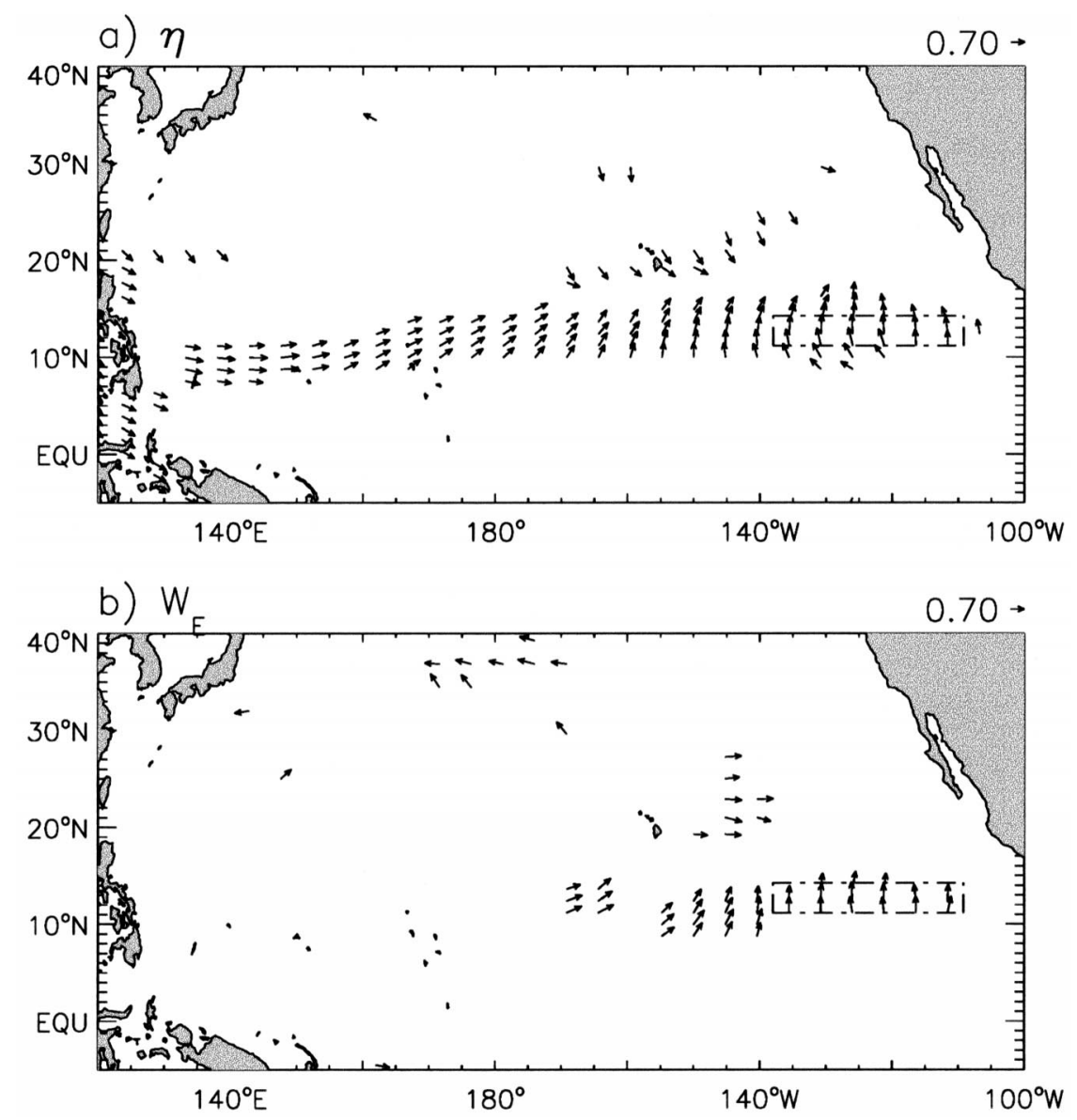

FIG. 8. (a) Propagation of $25.5 \sigma_{\theta}$ depth anomalies in the 7-10 yr range. The coherence in the $7-10$ yr range between $\eta$ in the box indicated by the dash-dot line (box 0 in Fig. 5) and $\eta$ at each grid point is given by the length of the arrows. Only arrows with coherence above the $90 \%$ significance level $(c o h=0.7)$ are drawn. Phase differences are given by the directions of the arrows, the convention being that arrows pointing due north correspond to zero phase lags, and positive phase lags are associated with a clockwise rotation of the arrows. An arrow that points due east indicates a lag of $90^{\circ}$. (b) Same as in (a), but for the Ekman pumping $W_{E}$.

very close to zero at the low-frequency end of the coherent band to $\sim 90^{\circ}$ at higher frequencies.

The presence of friction can significantly alter phase relationships between forcing and response. As an example, if Rayleigh friction is considered and a frictional timescale of 4 months is assumed, the expected phase difference between the two signals would be the one shown by the dash-dot line in Fig. 10d. At periods much longer than the frictional timescale the signals can be expected to be in phase, while for periods comparable or shorter than the frictional timescale the signals are approximately in quadrature, as in a frictionless system. How large is the friction in the model? We will see in section 4 that reasonable frictional timescales for the model are much longer than the one used in Fig. 10d. However, the superposition of the local response to Ekman pumping and the Rossby waves generated at the eastern boundary of the forcing region can result in very small phase lags between $W_{E}$ and $\eta$, as found in Fig. $10 \mathrm{a}$.

To discriminate between local forcing and remote forcing we perform cross-spectral analysis between thermocline displacement and Ekman pumping using the series of boxes in Fig. 5. For each box we compute the coherence of $\eta$ in that box with both $W_{E}$ in the same box and $W_{E}$ in box 0 . The results are shown in Fig. 11 . In each box, significant coherence between $\eta$ and $W_{E}$ (dot-dash line in Fig. 11) in the 7-10 yr spectral band, is found only in the first $4-5$ boxes (e.g., east of the date line), and the time lags between the two signals (not shown) are only of a few months. West of the date line, significant coherence is found only at periods shorter than $\sim 5$ yr. These results are consistent with Fig. 9b and add information about the frequency dependence of the $W_{E}-\eta$ correlation. When the cross-spectra between $\eta$ in each box and $W_{E}$ in box 0 are considered (solid 
a) $W_{E}$ standard deviation

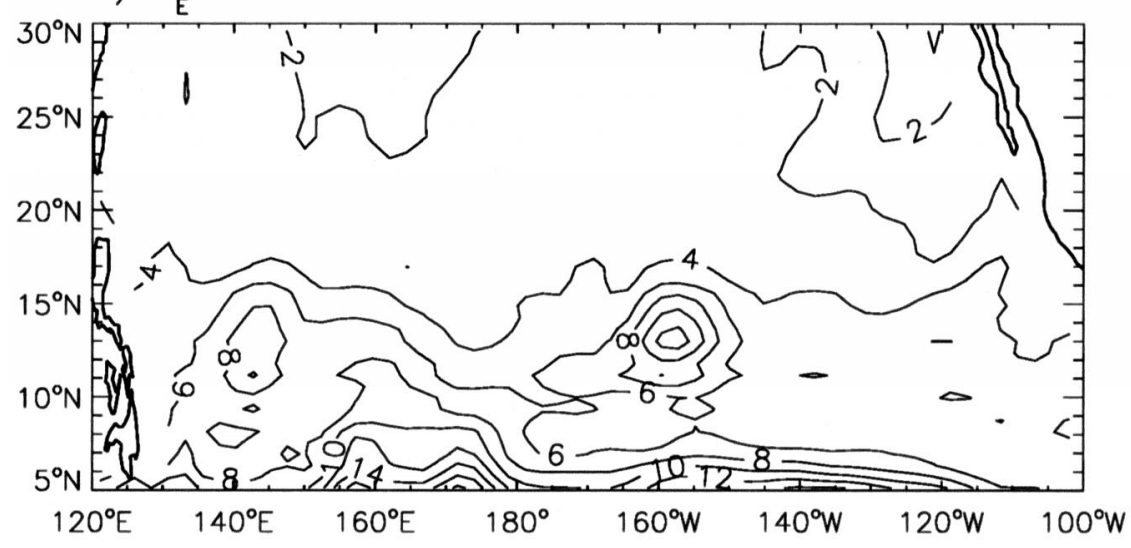

b) $\mathrm{W}_{\mathrm{E}}-\eta$ correlation

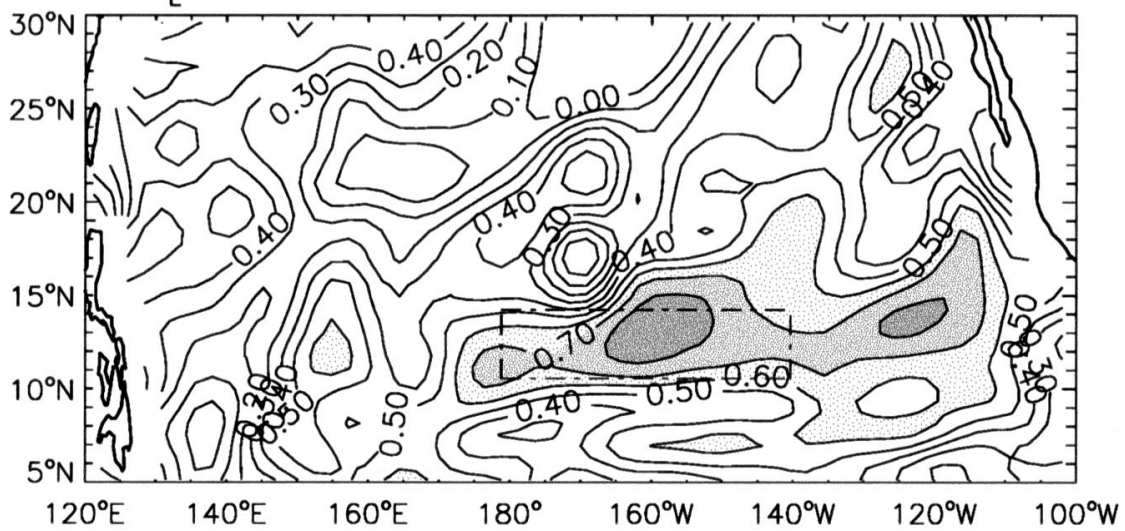

FIG. 9. (a) Standard deviation of the Ekman pumping anomalies. Units are $10^{-5} \mathrm{~cm} \mathrm{~s}^{-1}$. (b) Instantaneous correlation between Ekman pumping anomalies and $25.5 \sigma_{\theta}$ isopycnal depth anomalies. Note that the sign of the depth anomalies has been reversed, so that positive correlations correspond to negative $W_{E}^{\prime}$ and positive $\eta^{\prime}$ (deepening of the isopycnal), and vice versa. Contour interval is 0.1 . Values larger than 0.6 are shaded.

line in Fig. 11), significant coherence between the two signals in the 7-10 yr band is found all the way to the western boundary, with increasing lags. Significant coherence is consistently found also at $2-4$ yr periods, which correspond to the ENSO timescales.

East of the date line, decadal $\eta$ anomalies are coherent with the Ekman pumping in box 0 at increasing lags (indicative of propagation) while remaining approximately in phase with the local forcing. This suggests that east of the date line the $W_{E}$ anomalies themselves propagate westward. We clarify this point by applying cross-spectral analysis to the $W_{E}$ field in the same fashion used for the isopycnal depth anomalies. The result is presented in Fig. 8b, showing coherences and phase lags in the 7-10 yr band between $W_{E}$ at each model grid point and $W_{E}$ in box 0 (indicated by the dot-dash line in Fig. 8b). The conventions are the same as for Fig. $8 \mathrm{a}$, and only coherences above the $90 \%$ significance level are plotted. The Ekman pumping anomalies in this low-frequency range remain significantly coherent in the latitude band of interest as far west as $\sim 170^{\circ} \mathrm{W}$, as al- ready seen in Fig. 6. Phase lags are increasing westward (as shown by the clockwise rotation of the arrows), an indication of propagation. As for the isopyncal depth anomalies, an estimate of the phase speed is made by considering the phase lags among the boxes in Fig. 5, and relating them to the distances between boxes. The analysis is performed only west of $175^{\circ} \mathrm{W}$ where the $W_{E}$ signals are coherent. The result is shown in Fig. 7d, leading to an estimate for the phase speed, in a least squares sense, of $\sim 9 \mathrm{~cm} \mathrm{~s}^{-1}$.

\section{d. Summary}

The main points that have emerged from the analysis of the model signal presented in this section are the following:

- The band of variability at $10^{\circ}-15^{\circ} \mathrm{N}$ is associated with adiabatic displacements of the thermocline.

- These disturbances have a large fraction of energy in the 7-10 yr spectral band and appear to propagate 

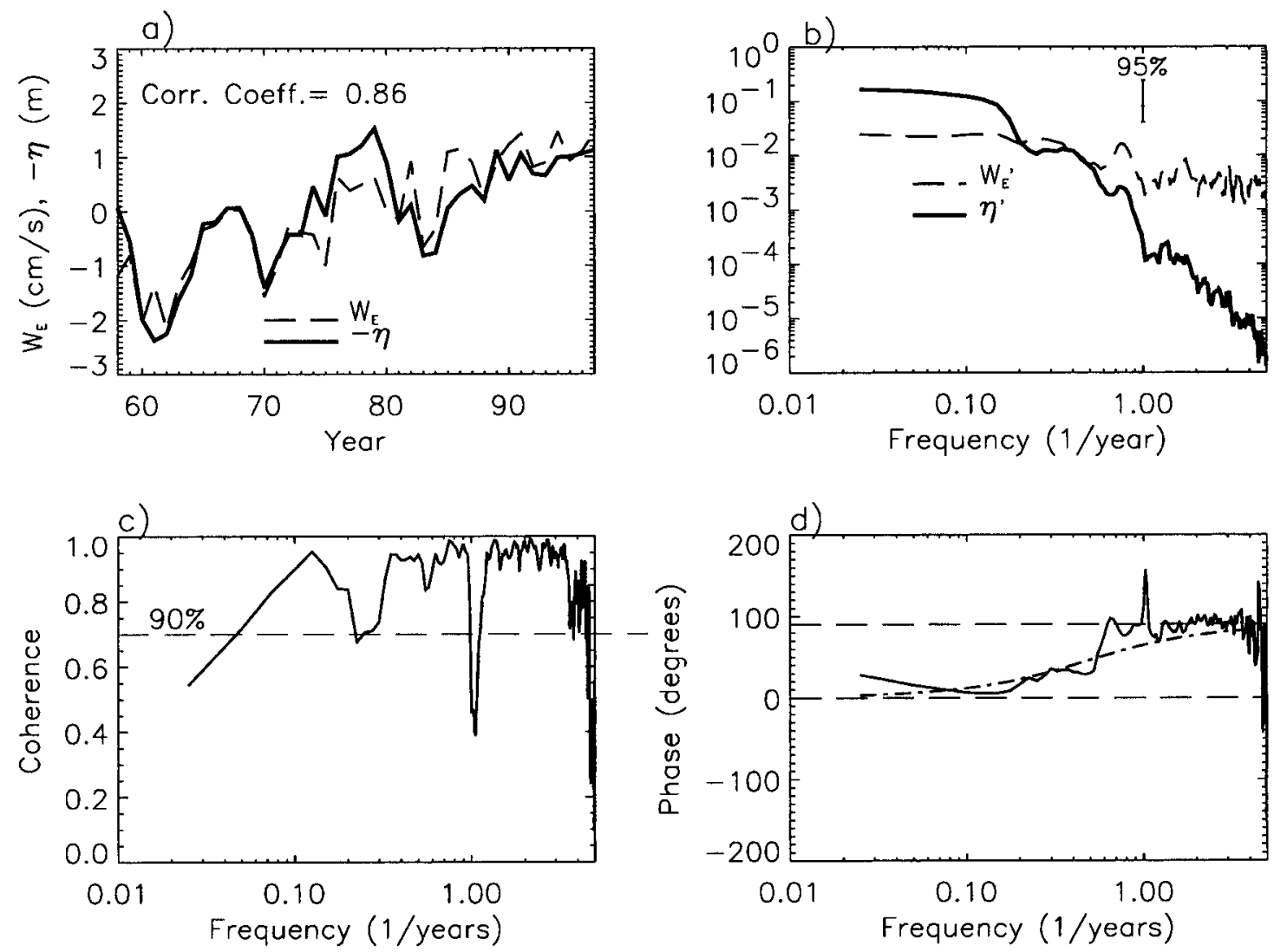

FIG. 10. (a) Time series of anomalous Ekman pumping (annual means, dashed line) averaged over the region $179^{\circ} \mathrm{E}-140^{\circ} \mathrm{W}, 11^{\circ}-14^{\circ} \mathrm{N}$, and time series of the depth anomaly of the $25.5 \sigma_{\theta}$ isopycnal (annual means, thick solid line) averaged over the same area. Notice that the sign of the depth anomalies has been reversed. The two time series are normalized to unit standard deviation. (b) Spectra of the time series in (a), based on monthly anomalies. (c) Coherence of the time series in (a). Monthly anomalies were used (seasonal cycle removed), explaining the low coherence at the annual period. The dashed line indicates the 90\% significance level. (d) Phase differences between the two time series in (a). $0^{\circ}$ and $90^{\circ}$ phase lags are indicated by the dashed lines, while the dot-dash line indicates the expected phase lag assuming a Rayleigh frictional timescale of 4 months.

westward with phase speeds varying from $\sim 13 \mathrm{~cm}$ $\mathrm{s}^{-1}$ east of the date line to $\sim 20 \mathrm{~cm} \mathrm{~s}^{-1}$ west of the date line.

- East of the date line, the ocean model signal is significantly coherent with the local Ekman pumping at a lag of a few months, while west of the date line the largest coherences between the two signals are found at high frequencies (periods shorter than $\sim 5 \mathrm{yr}$ ).

- East of the date line, decadal Ekman pumping anomalies themselves propagate westward with a phase speed of $\sim 9 \mathrm{~cm} \mathrm{~s}^{-1}$.

In the next section, we investigate whether the characteristics of the variability identified in this section can be explained in terms of forced baroclinic Rossby waves.

\section{A dynamical interpretation}

a. Free Rossby waves phase speeds

First of all, we need to assess how similar the phase speeds of the model signal are to the phase speeds of the free baroclinic Rossby waves in the model. To determine baroclinic Rossby waves phase speeds, we use the WKB approximation (Morse and Feshbach 1953), closely following the procedure outlined in Chelton et al. (1998). The baroclinic Rossby radius for mode $n$ is estimated as

$$
\lambda_{n}^{\mathrm{WKB}}=\frac{1}{f n \pi} \int_{-H}^{0} N d z
$$

where $n$ is the mode number, $f$ is the Coriolis parameter, $H$ is the ocean depth, and $N(z)$ is the buoyancy frequency. At each geographical location, the Rossby radii, as well as the vertical structure of the modes, depend uniquely upon the local vertical stratification. As discussed by Chelton et al. (1998), the WKB approximation is accurate only where $N(z)$ varies slowly. So, in the upper part of the water column, where the vertical scale of $N(z)$ is short, we can expect the WKB approximation to fail. However, Chelton et al. (1998) show that even in the areas of largest $N(z)$ variations the vertical structures found with this method are a very close 

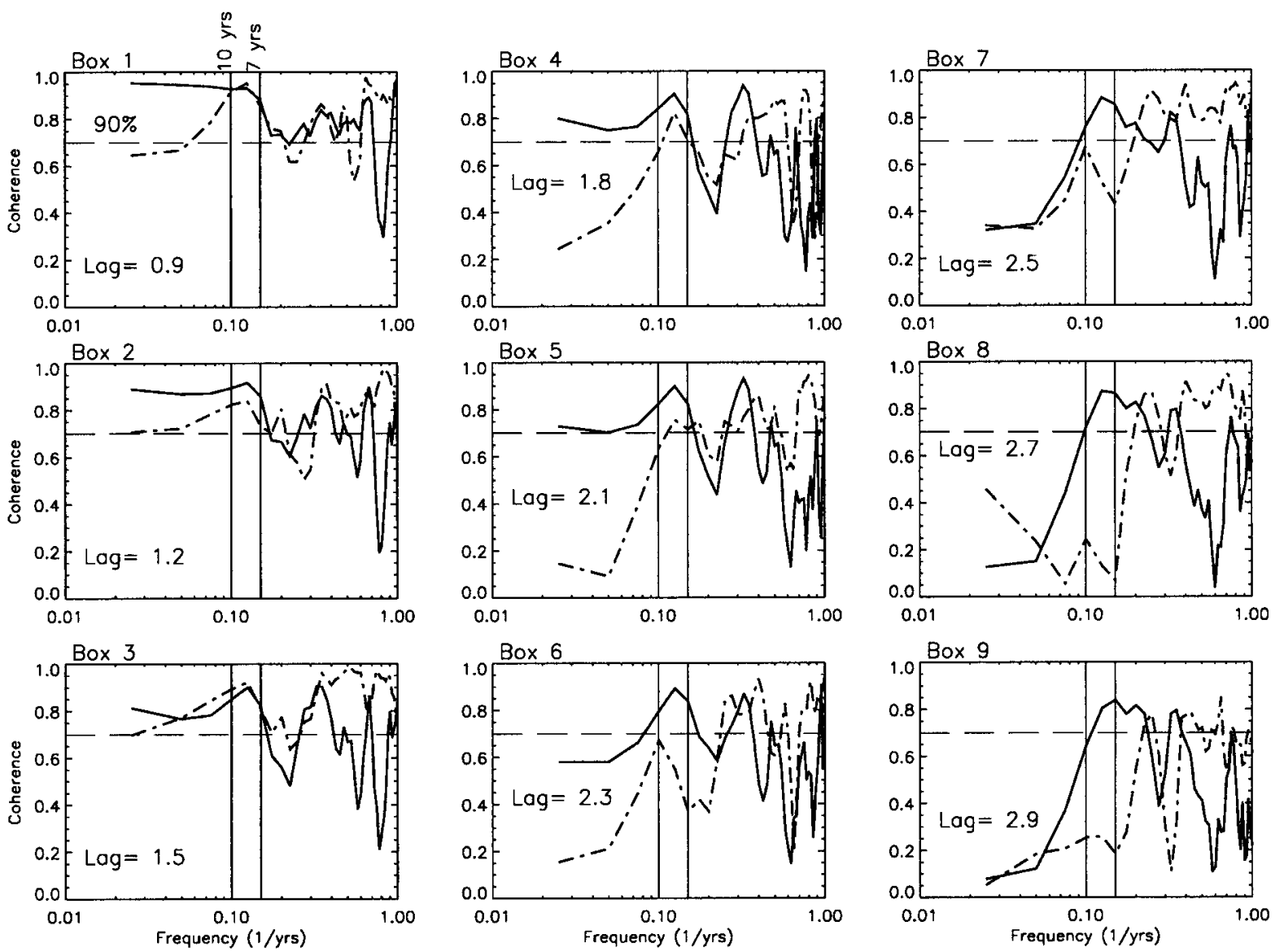

FIG. 11. Coherence between $25.5 \sigma_{\theta}$-depth anomalies in boxes 1 to 9 (from top to bottom, left to right) and the Ekman pumping in box 0 (thick solid lines), and coherence between $\eta$ in boxes $1-9$ and $W_{E}$ in the same box (dot-dash line). Monthly anomalies were used. Boxes are defined in Fig. 5. In each panel the thin vertical solid lines highlight the frequency bands with periods from 7 to $10 \mathrm{yr}$, and the dashed lines indicate the $90 \%$ significance level. Also, in each panel the time lag (in years) between $\eta$ in the corresponding box and $W_{E}$ in box 0 is indicated.

approximation to numerical estimates. They also show that the WKB Rossby radii are even less sensitive to the validity of the assumption of the WKB approximation, with discrepancies between Rossby radii obtained with the WKB approximation and Rossby radii computed numerically of the order of $10 \%$. Thus, we can expect that the Rossby radii and phase speeds estimated for the model with the WKB method are a good approximation of the true values.

The longitudinal variation of $\lambda^{\text {WKB }}$ for the first, second, and third baroclinic Rossby wave modes at $13.6^{\circ} \mathrm{N}$ is shown in Fig. 12a. For the first mode, the Rossby radius at this latitude increases from approximately 85 $\mathrm{km}$ close to the eastern boundary to approximately 95 $\mathrm{km}$ close to the western boundary due to the deepening of the thermocline toward the west. This estimate is in very good agreement with what computed by Chelton et al. (1998) from observations. The radius of deformation for the second mode is approximately $45 \mathrm{~km}$, while $\lambda_{3}^{\mathrm{WKB}}$ is approximately $30 \mathrm{~km}$.

In section 3 we have estimated the zonal wavelength of the signal to be much larger than the basin width, while a lower limit for the meridional wavelength was estimated to be $\sim 20^{\circ}$ of latitude. In Fig. 12b we show the longitudinal variation of the phase speeds at $13.6^{\circ} \mathrm{N}$ for the first three modes, in the long wave limit (thick lines), and assuming a meridional wavelength of $20^{\circ}$ (thin lines). For the second and third modes, the longwave approximation is very good, yielding phase speeds that are practically coincident with the phase speeds obtained for a $20^{\circ}$ meridional wavelength (thin lines and thick lines are indistinguishable in Fig. 12b). Phase speeds are about $2 \mathrm{~cm} \mathrm{~s}^{-1}$ for mode 3 , and $4-5 \mathrm{~cm} \mathrm{~s}^{-1}$ for mode 2 , increasing slightly from the eastern to the western side of the basin. For mode 1, on the other hand, the meridional wavenumber is closer to $\lambda_{1}^{-2}$ so that the phase speeds in the long-wave limit are $\sim 1 \mathrm{~cm}$ $\mathrm{s}^{-1}$ greater than those estimated from Eq. (8) assuming a meridional wavelength of $20^{\circ}$. The values that we obtain for mode 1 in the long-wave limit increase from $\sim 16 \mathrm{~cm} \mathrm{~s}^{-1}$ close to the eastern boundary to $\sim 19-20$ $\mathrm{cm} \mathrm{s}^{-1}$ close to the western boundary. 
a) Rossby radius (WKB) $-13.6^{\circ} \mathrm{N}$

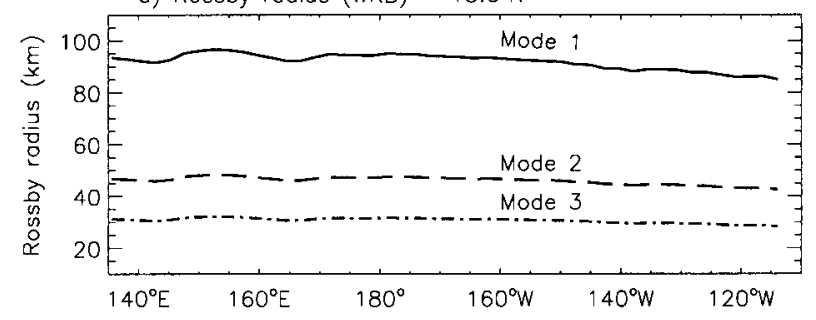

b) Phase speed (WKB) $-13.6^{\circ} \mathrm{N}$

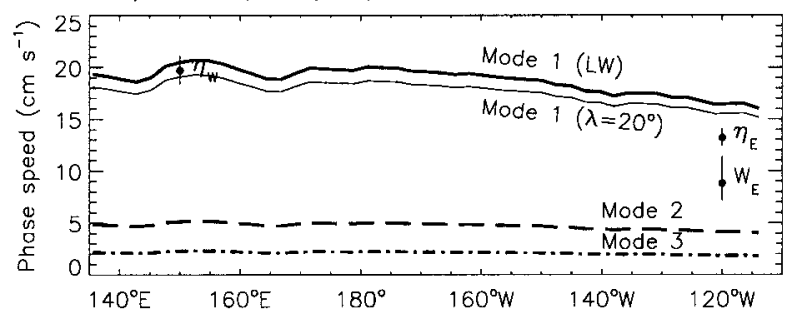

FIG. 12. (a) Longitudinal variation of the Rossby radii of deformation at $13.6^{\circ} \mathrm{N}$ for the baroclinic modes 1 (solid line), 2 (dashed line), and 3 (dot-dashed line). (b) Longitudinal variation of Rossby wave phase speed at $13.6^{\circ} \mathrm{N}$ for mode 1 (solid line), mode 2 (dashed line), and mode 3 (dot-dashed line). Thick lines indicate the phase speeds in the long-wave limit, while thin lines are for the phase speeds computed assuming a meridional wavelength of $20^{\circ}$ of latitude. The phase speed estimates for the $W_{E}$ anomalies east of $175^{\circ} \mathrm{W}\left(W_{E}\right)$, for the thermocline displacement east of $175^{\circ} \mathrm{E}\left(\eta_{E}\right)$, and thermocline displacement west of $175^{\circ} \mathrm{W}\left(\eta_{W}\right)$ are also shown for comparison. The $95 \%$ confidence limits for these phase speeds have been computed by assuming that the distribution of lags for each distance in Fig. 7 is Gaussian, with standard deviation independent of distance, and using the Student's tdistribution with $(n-2)$ degrees of freedom, where $n$ is the total number of points in each scatter diagram in Fig. 7.

Figure $12 \mathrm{~b}$ also shows the propagation speeds estimated for the model east of the date line $\left(\eta_{E}\right)$, and west of the date line $\left(\eta_{W}\right)$. The propagation speed of Ekman pumping anomalies east of the date line is indicated with $W_{E}$. West of the date line, the $\eta$ propagation speed is very close to the phase speed of the free baroclinic Rossby waves, while in the eastern side of the basin $\eta$ anomalies tend to be slower than free Rossby waves, but faster than the $W_{E}$ anomalies.

A possible interpretation of these results is that the decadal model signal mainly consists of Rossby waves forced by the westward propagating Ekman pumping anomalies east of the date line, while west of the date line it is primarily composed of freely propagating Rossby waves. We test this hypothesis in the next section.

\section{b. A simple model}

We use the familiar quasigeostrophic Rossby wave equation decomposed in baroclinic modes and forced by Ekman pumping (Gill and Clark 1974; Cane 1984; Shankar et al. 1996) in the long-wave limit:

$$
\frac{\partial \eta}{\partial t}-c_{n} \frac{\partial \eta}{\partial x}=-b_{n} W_{E}(x, t)-R \eta
$$

where $c_{n}=\beta \lambda_{n}^{2}$ is the phase speed of the long, mode $n$, free baroclinic Rossby waves (with $\beta$ being the meridional gradient of $f$ ); $b_{n}$ is the projection of the Ekman pumping, assumed to be a body force over a thin surface layer, onto mode $n$; and $-R \eta$ is a Rayleigh friction term. Since the propagation speed of the OGCM signal is very close to the phase speed of the first baroclinic mode, we will focus on this mode (so that $c_{n}=c_{1}=c$ ), and for simplicity we will assume $b_{n}$ equal one. The question we ask is to which extent the variability at $10^{\circ}-15^{\circ} \mathrm{N}$ in the OGCM can be explained by equation (3) with the given forcing.

To develop our intuition, we start by considering the simple case in which the Ekman pumping oscillates at a frequency $\omega_{f}$, and propagates westward with a phase speed $c_{f}$ within the zonal band $x_{f} \leq x \leq 0$ :

$$
W_{E}= \begin{cases}W_{o} e^{i \omega_{f}\left(t+x / c_{f}\right)}, & x_{f} \leq x \leq 0 \\ 0, & \text { elsewhere. }\end{cases}
$$

Here $x=0$ corresponds to the eastern edge of the forced region, and not necessarily to the eastern boundary of the basin. We only consider zonal propagation, so no $y$-dependence is explicitely included here. For simplicity, frictional processes are neglected.

In the long-wave limit the area east of the forcing band is unperturbed:

$$
\eta=0 \text { for } x \geq 0 \text {. }
$$

Within the forcing band, the solution is the superposition of two traveling waves, one propagating at $c_{f}$ and the other propagating at the phase speed of the free Rossby waves $c$ :

$$
\eta=-\frac{W_{o}}{i \omega_{f}\left(1-\frac{c}{c_{\mathrm{f}}}\right)}\left[e^{i \omega_{f}\left(t+x / c_{f}\right)}-e^{i \omega_{f}(t+x / c)}\right] .
$$

The two components have the same amplitude but opposite signs to satisfy the boundary condition at $x=$ 0 . Equation (6) can be rewritten in the form:

$$
\eta=\frac{2 W_{o}}{c \alpha} e^{i \omega_{f}(t+x / 2 \tilde{c})} \sin \left(\frac{\alpha}{2} x\right)
$$

where

$$
\alpha=\frac{\omega_{f}}{c}\left(1-\frac{c}{c_{f}}\right) \quad \text { and } \quad \tilde{c}=\frac{c c_{f}}{c+c_{f}} .
$$

The solution propagates westward with a phase speed 2r. Assuming $c_{f} \sim 9 \mathrm{~cm} \mathrm{~s}^{-1}$ and $c \sim 16 \mathrm{~cm} \mathrm{~s}^{-1}$, the phase speed of the signal in (7) is $2 \tilde{c} \sim 11.5 \mathrm{~cm} \mathrm{~s}^{-1}$, so it is an intermediate value between the speed of the forcing and the speed of the free waves.

When $c_{f}$ approaches $c, \alpha$ tends to zero, and (7) becomes

$$
\eta=-\frac{W_{o}}{c}|x| e^{i \omega_{f}(t+x / 2 \tilde{c})}
$$



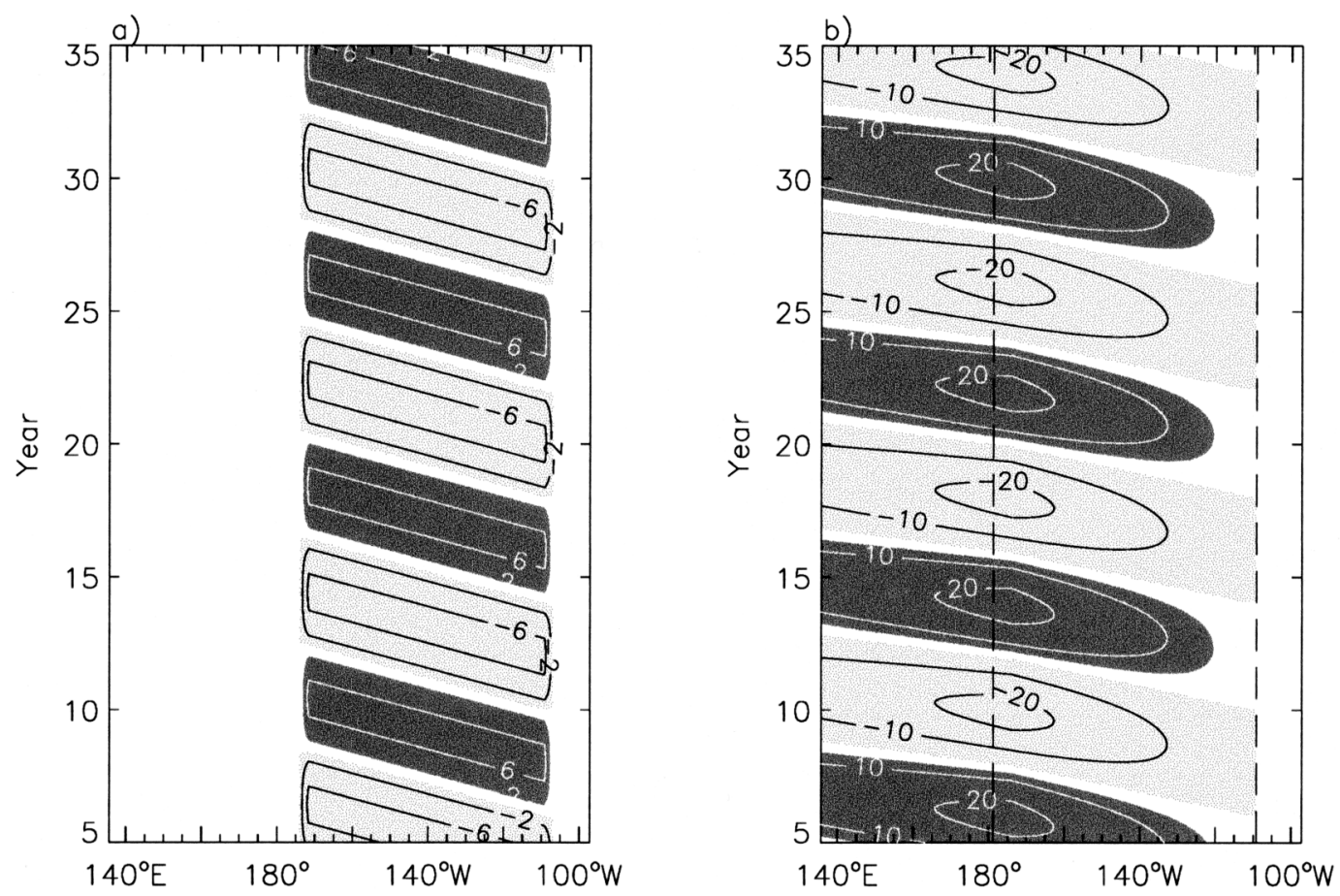

FIG. 13. (a) Hovmöller diagram of an oscillatory Ekman pumping which is different from zero only in the $180^{\circ}-$ $110^{\circ} \mathrm{W}$ longitude band. Within this band, $W_{E}$ propagates westward with a phase speed of $9 \mathrm{~cm} \mathrm{~s}^{-1}$. The $W_{E}$ amplitude is $7 \times 10^{-5} \mathrm{~cm} \mathrm{~s}^{-1}$. Contour interval is $4 \times 10^{-5} \mathrm{~cm} \mathrm{~s}^{-1}$. (b) Hovmöller diagram of the thermocline displacement computed from Eq. (3) when the Ekman pumping in (a) is used. Contour interval is $10 \mathrm{~m}$. Dashed lines indicate the forcing area.

so the amplitude of the ocean signal is an increasing function of $|x|$. Physically, this means that at propagation speeds very close to the free-wave phase speed the forcing is almost in phase with the wave and the amplitude of the response grows away from the eastern boundary of the forcing area, where the signal has to vanish.

West of the forcing area $\left(x<x_{f}\right)$ the solution to (3) is a travelling wave propagating at the phase speed of the free Rossby wave:

$$
\eta \sim-\frac{W_{o}}{c}\left|x_{f}\right| e^{i \omega_{f}(t+x / c)},
$$

for the case in which $c_{f} \sim c$. Notice that the amplitude of the solution west of the forcing area is set by the amplitude of the signal at $\left|x_{f}\right|$, which is the maximum amplitude achieved by the signal within the forcing area. Figure 13b shows the Hovmöller diagram of the $\eta$ field for the case in which $W_{E}$ is different from zero only in the longitude band $180^{\circ}-110^{\circ} \mathrm{W}$, where it oscillates at $\omega_{f}=2 \pi / 8 \mathrm{yr}$, and propagates at $c_{f}=9 \mathrm{~cm} \mathrm{~s}^{-1}$. The amplitude of the Ekman pumping is taken to be $7 \times$ $10^{-5} \mathrm{~cm} \mathrm{~s}^{-1}$ (Fig. 13a). For this idealized forcing case, the solution to (3) has been computed with the method of characteristics (Gill and Clarke 1974), using the longitude-dependent phase speed of the first baroclinic mode (Fig. 13b), and assuming a frictional timescale of $2.5 \mathrm{yr}$.
East of the date line, the signal propagates with a phase speed of $\sim 11.5 \mathrm{~cm} \mathrm{~s}^{-1}$ with increasing amplitude, while west of the date line the propagation speed increases to the speed of the free waves, a behavior very reminescent of what found in the OGCM. For the particular example considered here the time lag between the $W_{E}$ and $\eta$ time series at midbasin is of only a few months, and it is controlled by the relative phase speeds of the two traveling wave components in (6), the frictional timescale used here being much longer than the one estimated in Fig. 10d.

The very idealized Ekman pumping considered above gives rise to a solution that reproduces some of the major features of the OGCM solution. Figure $4 \mathrm{c}$ shows the evolution of the $\eta$ field along $13.6^{\circ} \mathrm{N}$ obtained from Eq. (3) forced with the observed $W_{E}$ along this latitude. The solution was obtained with the method of characteristics, using monthly $W_{E}$ values and assuming no depth changes along the eastern boundary. Comparison with Fig. 4b shows that the simple Rossby wave model reproduces the evolution of the thermocline depth along $13.6^{\circ} \mathrm{N}$ remarkably well. Differences are found close to the eastern boundary where the OGCM shows the presence of signals reflecting from the boundary into the interior, a process that we have purposely not included in the Rossby wave solution. Notice, however, that the boundary disturbances in Fig. $4 \mathrm{~b}$ decay within $20^{\circ}-30^{\circ}$ from the eastern boundary and their sign is often op- 
posite to the sign of the anomalies west of $\sim 120^{\circ} \mathrm{W}$. Thus, the variability exhibited by the OGCM along $13.6^{\circ} \mathrm{N}$ away from the eastern boundary appears to mainly consists of wind forced Rossby waves.

Why do the eastern boundary disturbances play such a minor role as a source of variability in the interior? Thermocline depth variations along the boundary are as large as $10-15 \mathrm{~m}$, as we will see in section 5 . Their contribution to the thermocline variability at a point $x$ and at time $t$ is

$$
\eta_{b}(x, t)=\eta_{b}\left(x_{e}, t-\tau\right) e^{-R \tau}
$$

where $x_{e}$ is the longitude of the eastern boundary at the given latitude, and

$$
\tau=\int_{x_{e}}^{x} \frac{d \xi}{c(\xi)}
$$

is the travel time of a signal propagating from the eastern boundary to point $x$ with a phase speed $c$. Assuming a propagation speed of $15 \mathrm{~cm} \mathrm{~s}^{-1}$ and a frictional timescale of $2.5 \mathrm{yr}$, the attenuation factor for the westward propagating boundary signal over $30^{\circ}$ of longitude would only be 0.7 , smaller than what is implied by Fig. 4b. It is plausible that friction is larger close to the boundary. It is also possible that a large fraction of the boundary disturbance projects on higher, and slower, baroclinic modes that would decay closer to the boundary. A conclusive explanation is still missing.

In section 3 we have seen that local correlations and coherences between the $\eta$ field and $W_{E}$ field are larger in the eastern side of the basin and tend to drop west of the date line where significant coherences are found only at high frequencies. What is the role played by the Ekman pumping in the western half of the basin? Figure $4 \mathrm{~d}$ shows the solution to (3) when the Ekman pumping west of $180^{\circ}$ is set to zero. Although some high frequency features are missing in the solution west of the date line, compared with Figs. $4 b$ and $4 c$, the large-scale structure remains the same. Thus, we conclude that a large fraction of the low-frequency variability west of the date line is associated with Rossby waves forced in the eastern half of the basin. The westward propagation of decadal Ekman pumping anomalies east of the date line appears to be an aspect of the forcing that is crucial in producing a relatively large, and basinwide, low-frequency ocean response.

\section{Area of influence}

The results shown in Fig. 8a seem to indicate that after reaching the western boundary the signal at $13^{\circ} \mathrm{N}$ continues along the boundary both to the north and the south. The southern branch is of particular interest because the anomalies may reach the equator and affect the upper ocean thermal structure at the equator, and possibly influence ENSO characteristics. To assess the area of influence of the anomalies along $13^{\circ} \mathrm{N}$ we consider the $\eta$ time evolution along a circuit consisting of a segment along $13^{\circ} \mathrm{N}$, from east to west (Fig. 14a), a second segment along the western boundary, from $13^{\circ} \mathrm{N}$ to the equator (Fig. 14b), a third segment along the equator, from west to east (Fig. 14c), and a fourth segment along the eastern boundary, from the equator to $13.6^{\circ} \mathrm{N}$ (Fig. 14d). Most of the anomalies reaching the western boundary at $13^{\circ} \mathrm{N}$ can be followed along the western boundary all the way to the equator and along the equator. The amplitude of the anomalies along the equator is considerably reduced with respect to the values along $13^{\circ} \mathrm{N}$ with maximum depth anomalies of 5$10 \mathrm{~m}$. However, these anomalous depth conditions appear to persist over several years. Modeling studies (Zebiak and Cane 1987; Latif et al. 1993; Meehl et al. 2001) have shown that the amplitude of El Niño is strongly affected by the mean depth of the thermocline, a deeper thermocline giving rise to a weaker El Niño and vice versa. Thus, the anomalies in Fig. 14c have the potential to modulate ENSO on decadal timescales. Although Fig. 14 indicates a possible influence of the variability at $13^{\circ} \mathrm{N}$ upon the equatorial thermocline variability, the exact contribution of the $13^{\circ} \mathrm{N}$ waves versus Rossby waves generated at lower latitudes is not clear. Kessler (1991) has shown that Rossby waves outside the equatorial band $\left(8^{\circ} \mathrm{S}-8^{\circ} \mathrm{N}\right)$ have smaller net zonal transports than near-equatorial Rossby waves, and may play a minor role in setting the amplitude of equatorial Kelvin waves. Additional studies are necessary to elucidate and quantify the role of the $10^{\circ}-15^{\circ} \mathrm{N}$ band on equatorial variability.

Which dynamical processes control the propagation of the anomalies from $13^{\circ} \mathrm{N}$ to the equator? The maximum correlation between the signal at $13^{\circ} \mathrm{N}$ and the signal at the equator along the western boundary is achieved at a lag of $\sim 3$ months, leading to an estimate for the phase speed along the boundary of $\sim 20 \mathrm{~cm} \mathrm{~s}^{-1}$. The mean circulation south of $\sim 15^{\circ} \mathrm{N}$ includes a southward flowing western boundary current, the model Mindanao Current. However, the zonal scale of the boundary current is much narrower than the width of the boundary signal and its maximum speed at 200-m depth is only $\sim 14 \mathrm{~cm} \mathrm{~s}^{-1}$. Thus, it seems likely that the Rossby waves along $13^{\circ} \mathrm{N}$ continue toward the equator as coastal Kelvin waves and then reflect along the equator as equatorial Kelvin waves.

Do the equatorial anomalies reach the eastern boundary and continue northward along the boundary as coastal Kelvin waves? Figure $14 \mathrm{c}$ shows the presence of large isopycnal depth anomalies east of $\sim 120^{\circ} \mathrm{W}$, as large as $30-50 \mathrm{~m}$, but they seem unrelated to the thermocline variability west of $\sim 120^{\circ} \mathrm{W}$. The equatorial variability in the east is, in fact, dominated by ENSO with timescales of $\sim 2-4$ yr. The anomalies continue along the eastern boundary with amplitudes of 10-15 m, all the way to $13^{\circ} \mathrm{N}$ where reflections into the interior can be observed. However, as discussed in section 4, along $13^{\circ} \mathrm{N}$ the boundary disturbances only affect a relatively narrow longitude band close to the boundary, while the 

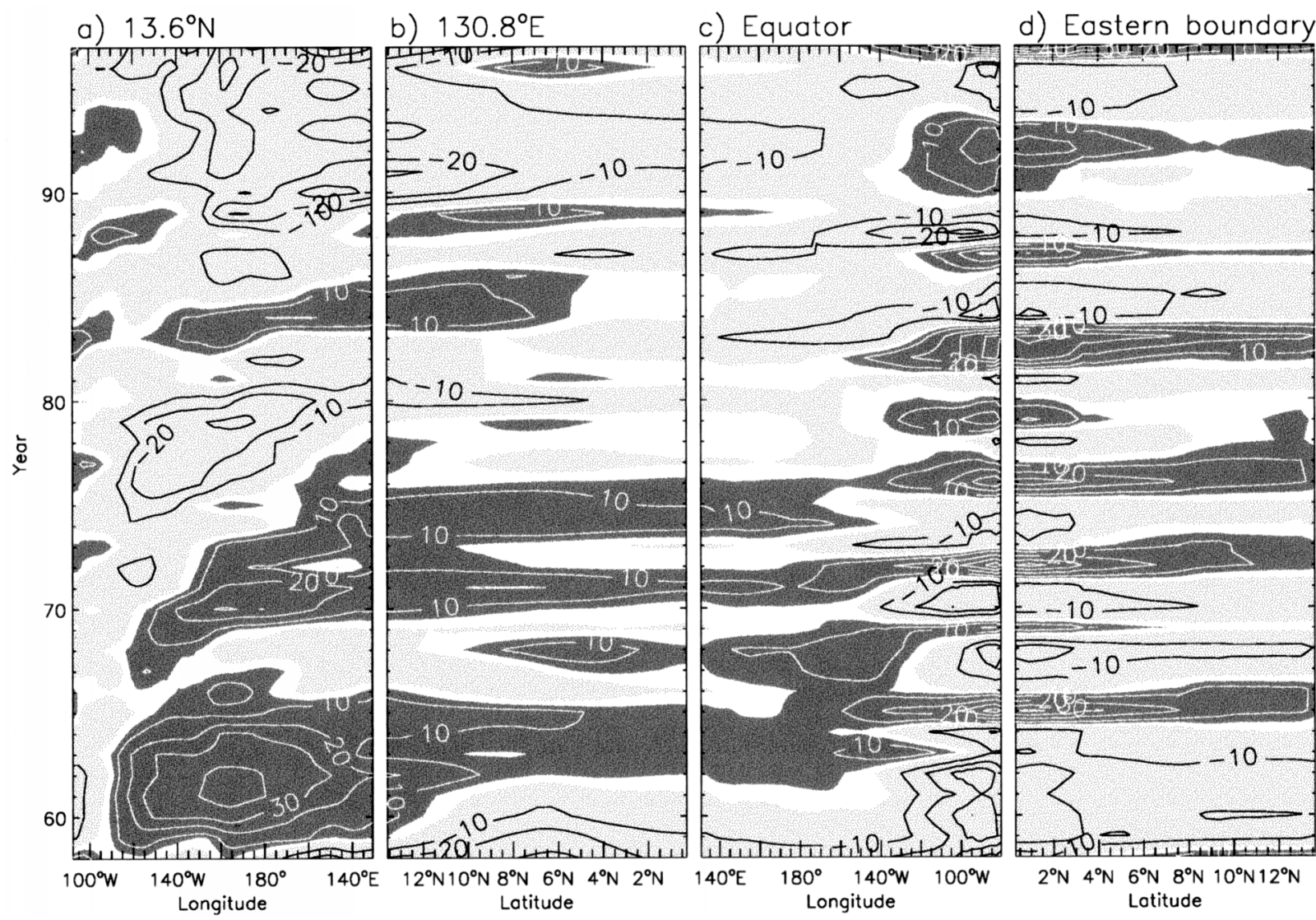

FIG. 14. Hovmöller diagram of $25.5 \sigma_{\theta}$ depth anomalies (in m) along (a) $13.6^{\circ} \mathrm{N}$ (plotted from east to west), (b) $130.8^{\circ} \mathrm{E}$ (plotted north to south), (c) equator (plotted from east to west), and (d) along the eastern boundary, from the equator to $13.6^{\circ} \mathrm{N}$. Time is increasing upward, so that anomalies are propagating westward along $13.6^{\circ} \mathrm{N}$. Light gray indicates negative anomalies, while dark gray is used for positive anomalies. Contour interval is $10 \mathrm{~m}$.

variability in the interior is mainly controlled by wind forcing. Using cross-spectral analysis, we find the propagation speed along the boundary to be $30-38 \mathrm{~cm} \mathrm{~s}^{-1}$ (there is a slight frequency dependence), very close to the value estimated by $\mathrm{K} 90\left(32 \mathrm{~cm} \mathrm{~s}^{-1}\right)$.

A Hovmöller diagram along a close circuit similar to the one in Fig. 14 was also computed by K90 for the period $1968-87$, using monthly values of observed $20^{\circ} \mathrm{C}$ isotherm depth anomalies (Fig. 24 in K90). If we compare K90's result with a similar Hovmöller diagram from the model, computed using monthly anomalies of the depth of the $20^{\circ} \mathrm{C}$ isotherm over the same 20 -yr period (not shown), we find that the evolution of the positive and negative events is very similar in both cases. Along $13^{\circ} \mathrm{N}$ the model exhibits larger depth anomalies in the area around $160^{\circ} \mathrm{W}$, but along the equator and eastern boundary the modeled and observed signals are generally of comparable magnitude.

\section{Discussion}

A large part of the thermocline variability in the model at $10^{\circ}-15^{\circ} \mathrm{N}$ is consistent with Rossby wave dynam- ics, given the spatial distribution and propagation characteristics of the Ekman pumping anomalies. However, there are some open questions. First of all, Rossby waves are found at all latitudes (Chelton and Schlax 1996), and Ekman pumping is likely to play a key role in their excitation (Qiu et al. 1997). Why is the thermocline variability particularly large in the $10^{\circ}-15^{\circ} \mathrm{N}$ band? Capotondi and Alexander (2001) have shown that the center of variability around $13^{\circ} \mathrm{N}$ coincides with an area of very large meridional gradients in mean thermocline depth. Meridional displacements of the thermocline can account for a large part of the temperature variability in that area. The relative importance of vertical displacements versus meridional displacements needs to be further investigated.

A second open question concerns aspects of the forcing. What determines the westward propagation of the Ekman pumping anomalies around $13^{\circ} \mathrm{N}$ in the $7-10 \mathrm{yr}$ spectral band? And what determines the long (decadal) timescale of the variability? Decadal timescales are very long for internal atmospheric processes. Is the westward propagation of the $W_{E}$ anomalies simply due to the presence of energy in that particular frequency-wavenumber 
area of a stochastic spectrum, or is it the result of some distinct physical process?

We have seen in Fig. 10b that the frequency spectrum of the Ekman pumping is indistinguishable from a white noise spectrum. Thus, a possible explanation for the timescale of the variability is that the Ekman pumping is primarily a stochastic process with energy in the frequency-wavenumber range corresponding to propagation speeds close to the speed of the oceanic first baroclinic Rossby wave mode. In this case the ocean would respond preferentially to the forcing in that part of the spectrum, effectively acting as a dynamical filter.

White (2000) has shown observational evidence of coupled Rossby waves in the tropical North Pacific. These are waves in which the surface signature of the oceanic signal induces an atmospheric response that reinforces the oceanic signal itself so that the wave can sustain itself against dissipation. The oceanic and atmospheric disturbances move westward in a phaselocked fashion at a speed slower than the free oceanic Rossby wave speed. This mechanism would justify the existence of westward propagating atmospheric signals at frequencies that are very low for atmospheric processes and also justify why the phase speed of the Ekman pumping anomalies is somewhat slower than the first mode baroclinic Rossby wave phase speed, as shown in Fig. 12b. Some preliminary analyses have not shown any significant correlation between model SSTs and Ekman pumping along $13^{\circ} \mathrm{N}$. Moreover, SST anomalies appear to have a standing character rather than to propagate in phase with the $W_{E}$ anomalies, as expected for coupled Rossby waves.

Since the thermocline anomalies along $13^{\circ} \mathrm{N}$ appear to propagate all the way to the equator, one could envision a coupled mechanism in which, after reaching the equator, the thermocline anomalies give rise to SST anomalies along the equator that would then affect the atmospheric circulation and produce Ekman pumping anomalies of the opposite sign in the Tropics. This mechanism would be similar to the one proposed by Schneider (2000), but in this case the anomalies reach the equator through wave propagation rather than by advection. Consequently, the timescales are much faster. At $13^{\circ} \mathrm{N}$ the anomalies cross the basin in $2-2.5$ years, and the southward propagation along the western boundary and along the equator is much faster than a year. So the total transit time from the eastern Pacific at $13^{\circ} \mathrm{N}$ to the equator is no longer than 3 years. Thus, even if the thermocline anomalies at the equator were large enough to induce an atmospheric feedback, this coupled mechanism would not explain the observed timescale.

Finally, it has been shown by Pierce et al. (2000) that atmospheric teleconnections are the dominant mechanism responsible for the large correlations between the low-frequency variability in the tropics and in midlatitudes. Analyses of a coupled GCM (the ECHO-2 model) and some uncoupled atmospheric general circulation model simulations forced with midlatitude SST anom- alies seem to indicate that the midlatitude decadal SST anomalies induce changes in the surface wind stress that extend all the way to the Tropics. The Pierce et al. results suggest that the decadal timescale of the signal around $13^{\circ} \mathrm{N}$ could arise from a basinwide atmospheric response to midlatitude low-frequency SST anomalies. Ekman pumping anomalies east of $\sim 160^{\circ} \mathrm{W}$ in the $10^{\circ}-15^{\circ} \mathrm{N}$ band are highly correlated with the model SST variations in midlatitudes $\left(35^{\circ}-40^{\circ} \mathrm{N}, 170^{\circ} \mathrm{E}-170^{\circ} \mathrm{W}\right)$, but the maximum correlation $(-0.65)$ occurs when the $W_{E}$ anomalies lead the midlatitude SST anomalies by two years. Ekman pumping anomalies are also highly correlated with the model SST variations in the Niño-3 + Niño-4 region $\left(5^{\circ} \mathrm{S}-5^{\circ} \mathrm{N}, 160^{\circ} \mathrm{E}-90^{\circ} \mathrm{W}\right)$. In this case the largest correlation coefficient is 0.74 , with equatorial SST variations leading the Ekman pumping variations by one year. The time series of equatorial and midlatitude SSTs also exhibit a trend similar to the one noticed in Fig. 10a, which appears to be a basinwide phenomenon.

The existence of the above correlations supports the hypothesis that the Ekman pumping variability around $13^{\circ} \mathrm{N}$ may be part of a larger-scale pattern of low-frequency variability extending from the equator to the midlatitudes. However, the physical mechanisms responsible for these correlations and for the associated lags are unclear. Further analyses with long time series from coupled and uncoupled simulations are necessary to elucidate these points.

\section{Conclusions}

In this study we have analyzed the nature of the thermocline variability in a relatively narrow latitude band extending from approximately $10^{\circ} \mathrm{N}$ to $15^{\circ} \mathrm{N}$ with largest amplitudes around $13^{\circ} \mathrm{N}$. The analysis has been performed using the output from an ocean GCM simulation driven by observed atmospheric forcing over the period 1958-97.

Our major findings are as follows:

- The ocean variability is associated with westward propagating baroclinic Rossby waves characterized by periods longer than $\sim 7 \mathrm{yr}$.

- These waves are forced by westward propagating Ekman pumping anomalies (phase speed $\sim 9 \mathrm{~cm} \mathrm{~s}^{-1}$ ) east of $\sim 180^{\circ}-170^{\circ} \mathrm{W}$. They propagate at a speed of $\sim 13 \mathrm{~cm} \mathrm{~s}^{-1}$, which is slower than the first baroclinic mode phase speed but faster than the phase speed of the forcing, and it may arise from the superposition of free and forced solutions. East of the date line, the phase speed of the Ekman pumping anomalies is close to the phase speed of the first baroclinic Rossby wave mode, thus explaining the large oceanic response as well as the large correlation with the forcing.

- West of the date line, the correlations between the oceanic signal and the local Ekman pumping are weaker and a large fraction of the variability consists 
of free waves propagating westward at the speed of the first baroclinic Rossby wave mode $\left(\sim 20 \mathrm{~cm} \mathrm{~s}^{-1}\right)$.

- After reaching the western boundary, the waves appear to propagate along the western boundary, both to the north and the south. The southward branch can be tracked all the way to the equator and along the equator and may contribute to low-frequency equatorial thermocline displacements.

Some questions raised by our findings include the origin of the westward propagation of the decadal Ekman pumping anomalies in the eastern half of the basin, the origin of the decadal timescales of the ocean signal, the relationship between decadal variability in the $10^{\circ}-15^{\circ} \mathrm{N}$ band and basin-scale decadal variability, and the possible impact of the thermocline variations along the equator on ENSO characteristics. Analyses of coupled models as well as sensitivity studies performed with more idealized models are necessary for answering these questions.

Acknowledgments. We would like to thank the NCAR Oceanography Section for making the model output available to us. Many thanks to R. Madden of NCAR for sharing with us his expertise in cospectral analysis. The constructive criticism of three anonymous Reviewers has greatly improved the manuscript. This work was supported by NOAA-GOALS Grant GC98-139.

\section{REFERENCES}

Bishop, J. K. B., and W. B. Rossow, 1991: Spatial and temporal variability of global surface solar irradiance. J. Geophys. Res., 96, $16839-16858$.

Cane, M. A., 1984: Modeling sea level during El Niño. J. Phys. Oceanogr., 14, 1864-1874.

Capotondi, A., and M. A. Alexander, 2001: The influence of thermocline topography on the oceanic response to fluctuating winds: A case study in the tropical North Pacific. Advances in Mathematical modelling of Atmosphere and Ocean dynamics, $\mathrm{P}$. F. Hodnett Ed., Kluwer, p. 119-124.

Cessi, P., 2000: Thermal feedback on wind stress as a contributing cause of climate variability. J. Climate, 13, 232-244.

Chelton, D. B., and M. G. Schlax, 1996: Global observations of oceanic Rossby waves. Science, 272, 234-238.

__ R. A. de Szoeke, and M. G. Schlax, 1998: Geographical variability of the first baroclinic Rossby radius of deformation. $J$. Phys. Oceanogr., 28, 433-460.

Douglas, A. V., D. R. Cayan, and J. Namias, 1982: Large-scale changes in North Pacific and North American weather patterns in recent decades. Mon. Wea. Rev., 110, 1851-1862.

Frankignoul, C., P. Müller, and E. Zorita, 1997: A simple model of the decadal response of the ocean to stochastic wind forcing. $J$. Phys. Oceanogr., 27, 1533-1546.

Gent, P. R., and J. C. McWilliams, 1990: Isopycnal mixing in ocean circulation models. J. Phys. Oceanogr., 20, 150-155.

_ , F. O. Bryan, G. Danabasoglu, S. C. Doney, W. R. Holland, W. G. Large, and J. C. McWilliams, 1998: The NCAR Climate System Model global ocean component. J. Climate, 11, 12871306.

Gill, A. E., and A. J. Clarke, 1974: Wind-induced upwelling, coastal currents and sea-level changes. Deep-Sea Res., 21, 325-345.

Goddard, L., and N. E. Graham, 1997: El Niño in the 1990s. J. Geophys. Res., 102, $10423-10436$.
Goodman, J., and J. Marshall, 1999: A model of decadal middlelatitude atmosphere-ocean coupled modes. J. Climate, 12, 621641.

Graham, N. E., 1994: Decadal-scale climate variability in the tropical and North Pacific during the 1970s and 1980s: Observations and model results. Climate Dyn., 6, 135-162.

— T. P. Barnett, R. Wilde, M. Ponater, and S. Schubert, 1994: On the role of tropical and midlatitude SSTs in forcing annual to interdecadal variability in the winter Northern Hemisphere circulation. J. Climate, 7, 1416-1442.

Grötzner, A., M. Latif, and T. P. Barnett, 1998: A decadal climate cycle in the North Atlantic ocean as simulated by the ECHO coupled GCM. J. Climate, 11, 831-847.

Gu, D., and S. G. H. Philander, 1997: Interdecadal Climate fluctuations that depend on exchanges between the tropics and extratropics. Science, 275, 805-807.

Haney, R. L., 1971: Surface thermal boundary condition for ocean circulation models. J. Phys. Oceanogr., 1, 241-248.

Jin, F.-F., 1997: A theory of interdecadal climate variability of the North Pacific ocean-atmosphere system. J. Climate, 10, 324338.

_ J. J. Neelin, and M. Ghil, 1994: El Niño on the devil's staircase: Annual subharmonic steps to chaos. Science, 264, 70-72.

Kalnay, E., and Coauthors, 1996: The NCEP/NCAR 40-Year Reanalysis Project. Bull. Amer. Meteor. Soc., 77, 437-471.

Kessler, W. S., 1990: Observations of long Rossby waves in the northern tropical Pacific. J. Geophys. Res., 95, 5183-5217.

_- 1991: Can reflected extra-equatorial Rossby waves drive ENSO? J. Phys. Oceanogr., 21, 444-452.

Kleeman, R., and S. B. Power, 1994: Limits to predictability in a coupled ocean-atmosphere model due to atmospheric noise. $\mathrm{Tel}$ lus, 46A, 529-540.

Knudson, T. R., and S. Manabe, 1998: Model assessment of decadal variability and trends in the tropical Pacific Ocean. J. Climate, 11, 2273-2296.

Large, W. G., and S. Pond, 1982: Sensible and latent heat flux measurements over the ocean. J. Phys. Oceanogr., 12, 464-482.

_ J. C. McWilliams, and S. C. Doney, 1994: Oceanic vertical mixing: A review and a model with a nonlocal boundary layer parameterization. Rev. Geophys., 32, 363-403.

_ G. Danabasoglu, and S. C. Doney, 1997: Sensitivity to surface forcing and boundary layer mixing in a global ocean model: annual-mean climatology. J. Phys. Oceanogr., 27, 2418-2447.

— - _ J. C. McWilliams, P. R. Gent, and F. O. Bryan, 2001: Equatorial circulation of a global ocean climate model with anisotropic horizontal viscosity. J. Phys. Oceanogr., 31, 518-536.

Latif, M., and T. P. Barnett, 1994: Causes of decadal climate variability over the North Pacific and North America. Science, 266, 634-637.

— Pacific and North America: dynamics and predictability. J. Climate, 9, 2407-2423.

_, A. Sterl, E. Maier-Reimer, and M. M. Junge, 1993: Climate variability in a coupled GCM. Part I: The tropical Pacific. $J$. Climate, 6, 5-21.

Lau, N.-C., 1997: Interactions between global SST anomalies and the midlatitude atmospheric circulation. Bull. Amer. Meteor. Soc., 78, 21-33.

_ of the tropical and extratropical SST anomalies in the variability of the global atmosphere-ocean system. J. Climate, 7, 11841207.

Liu, Z., 1999: Forced planetary wave response in a thermocline gyre. J. Phys. Oceanogr., 29, 1036-1055.

Lysne, J., and C. Deser, 2002: Wind-driven thermocline variability in the Pacific: A model/data comparison. J. Climate, in press.

Mantua, N. J., S. R. Hare, Y. Zhang, J. M. Wallace, and R. Francis, 1997: A Pacific interdecadal climate oscillation with impacts on salmon production. Bull. Amer. Meteor. Soc., 78, 1069-1079.

Meehl, G. A., P. R. Gent, J. M. Arblaster, B. L. Otto-Bliesner, E. C. 
Brady, and A. Craig, 2001: Factors that affect the amplitude of El Niño in global coupled climate models. Climate Dyn., 17, 515-526.

Meyers, G., 1979: On the annual Rossby wave in the tropical North Pacific Ocean. J. Phys. Oceanogr., 9, 663-674.

Morse, P. M., and H. Feshbach, 1953: Methods of Theoretical Physics. McGraw-Hill, 997 pp.

Münnich, M., M. A. Cane, and S. E. Zebiak, 1991: A study of selfexcited oscillations in a tropical ocean-atmosphere system. Part II: Nonlinear cases. J. Atmos. Sci., 48, 1238-1248.

Neelin, J. D., and W. Weng, 1999: Analytical prototypes for oceanatmosphere interaction in midlatitudes. Part I: Coupled feedbacks as a sea surface temperature dependent stochastic process. J. Climate, 12, 697-721.

Nitta, T., and S. Yamada, 1989: Recent warming of tropical sea surface temperature and its relationship to the Northern Hemisphere Circulation. J. Meteor. Soc. Japan, 67, 375-383.

Pierce, D. W., T. P. Barnett, and M. Latif, 2000: Connections between the Pacific Ocean Tropics and midlatitudes on decadal timescales. J. Climate, 13, 1173-1194.

Qiu, B., W. Miao, and P. Müller, 1997: Propagation and decay of forced and free baroclinic Rossby waves in off-equatorial oceans. J. Phys. Oceanogr., 27, 2405-2417.

Robertson, A. W., 1996: Interdecadal variability over the North Pacific in a multicentury climate simulation. Climate Dyn., 12, $227-241$.

Rossow, W. B., and R. A. Shiffer, 1991: ISCCP cloud data products. Bull. Amer. Meteor. Soc., 72, 2-20.

Schneider, N., 2000: A decadal spiciness mode in the tropics. Geophys. Res. Lett., 27, 257-260.

— A. J. Miller, M. A. Alexander, and C. Deser, 1999: Subduction of decadal North Pacific temperature anomalies: Observations and dynamics. J. Phys. Oceanogr., 29, 1056-1070.

Shankar, D., J. P. McCreary, W. Han, and S. R. Shetye, 1996: Dynamics of the East India Coastal Current 1 Analytic solutions forced by interior Ekman pumping and local alongshore winds. J. Geophys. Res., 101, 13 975-13991.

Spencer, R. W., 1993: Global oceanic precipitation from the MSU during 1979-91 and comparison to other climatologies. J. Climate, 6, 1301-1326.

Tanimoto, Y., N. Iwasaka, K. Hanawa, and Y. Toba, 1993: Characteristic variations of sea surface temperature with multiple time scales in the North Pacific. J. Climate, 6, 1153-1160.

Trenberth, K. E., 1990: Recent observed interdecadal climate changes in the Northern Hemisphere. Bull. Amer. Meteor. Soc., 71, 988993.

-, and J. W. Hurrell, 1994: Decadal atmosphere-ocean variations in the Pacific. Climate Dyn., 9, 303-319.

Wang, X. L., and C. F. Ropelewski, 1995: An assessment of ENSOscale secular variability. J. Climate, 8, 1584-1589.

White, W. B., 1977: Annual forcing of baroclinic long waves in the tropical North Pacific Ocean. J. Phys. Oceanogr., 7, 50-61.

_- 2000: Tropical coupled Rossby waves in the Pacific oceanatmosphere system. J. Phys. Oceanogr., 30, 1245-1264.

- , and J. F. T. Saur, 1981: A source of annual baroclinic waves in the eastern subtropical North Pacific. J. Phys. Oceanogr., 11, $1452-1462$

— , and — 1983: A source of interannual baroclinic waves in the eastern subtropical North Pacific. J. Phys. Oceanogr., 13, 531-544.

Xie, P., and P. A. Arkin, 1996: Analyses of global monthly precipitation using gauge observations, satellite estimates, and numerical model predictions. J. Climate, 9, 840-858.

Xie, S.-P., T. Kunitani, A. Kubokawa, M. Nonaka, and S. Hosoda, 2000: Interdecadal thermocline variability in the North Pacific for 1958-97: A GCM simulation. J. Phys. Oceanogr., 30, 27982813.

Yasuda, T., and K. Hanawa, 1997: Decadal changes in mode waters in the midlatitude North Pacific. J. Phys. Oceanogr., 27, 858870 .

Zhang, R. H., and Z. Liu, 1999: Decadal thermocline variability in the North Pacific: Two pathways around the subtropical gyre. $J$. Climate, 12, 3273-3296.

Zhang, Y., J. M. Wallace, and D. S. Battisti, 1997: ENSO-like interdecadal variability. J. Climate, 10, 1004-1020.

Zebiak, S. E., and M. A. Cane, 1987: A model of El Niño/Southern Oscillation. Mon. Wea. Rev., 115, 2262-2278. 